\title{
Analytical performance of the selective multianalyser Olympus AU 5200
}

\author{
H. Mayer, C. Luley, M. Behnke and H. Wieland \\ Abteilung fuir Klinische Chemie, Universitätsklinik der Albert-Lutwigs- \\ Universität, Freiburg, Freiburg, Germany
}

The analytical performance of a selective, automatic multianalyser - the Olympus AU 5200 - was tested and assessed for practicability, following ECCLS guidelines. Twenty-two analytes were tested and compared with the Olympus AU 5000 analyser. A Hitachi 747 analyser was also included in this survey in order to obtain correlation data for ISE measurements.

The imprecision data, expressed as median $C V$ values, were found to be below $2 \%$ in series for 21 parameters, and below 3\% for 19 paramaters from day to day. Creatinine measured with the kinetic Jaffe method obtained a median CV value of $4 \%$ in series, creatine phosphokinase showed the worst imprecision from day to day with a CV of $9 \%$. Slightly better precision values for the majority of all tests were found on the Olympus AU 5200 than on the AU 5000 analyser.

The recovery of the assigned values in 32 commercial control sera was between $95 \%$ and $105 \%$ for 14 tests. Five of the remaining tests yielded recoveries with deviations between $5 \%$ and 10\%, deviations above $10 \%$ showed albumine, alanine aminotransferase, aspartate aminotransferase and creatine phosphokinase. The accuracy of most test parameters was slightly better on the AU 5200 analyser than on the comparison instrument.

The range of linearity of the tested methods covered the range stated by the manufacturers; and no sample carry-over was detected. Most parameters tested yielded close correlation to those on the comparison instrument. Amylase measurements on both analysers correlate well but are not comparable without data correction due to different test methods. In addition, no drift effects were observed over a period of 9 hours.

The ion-selective-electrode unit performed well in terms of throughput, precision and stability over time. The whole system showed good practicability with respect to patient sample and reagent handling, a short training period of technicians, ease of system software, maintenence, a robust barcode reader and a flexible host communication procedure.

\section{Introduction}

The Olympus AU 5200 series of selective multianalysers is well suited for medium and large laboratories processing several thousand samples per day. This paper reports on the performance characteristics of the AU 5200 analyser comparing it with the AU 5000 analyser. The evaluation procedure followed ECGLS guidelines [1]. Although only a multicentre evaluation allows a truly representative assessment for an analyser, the evaluation data presented here give a first impression of the quality and performance of the instrument.

\section{The AU 5200}

The AU 5200 is constructed following a modular concept that originated from the AU 5000 instrument series. Any analyser consists of up to four basic identical units equipped with eight or 16 reagent lines. The stated sample throughput of 330 samples (300 samples with ISE unit), which is twice as much as that of an AU 5000 analyser, is achieved by two cuvette rings per unit with 240 cuvettes each. In an analyser equipped with eight reagent lines per module, 60 cuvettes are assigned to each chemistry channel (this compares with 24 cuvettes in a similar model of the series AU5000). A list of the main specifications of the AU 5200 analyser is given in table 1, along with a survey of possible configurations. Evaluation data on the comparison instrument AU 5000 has been published by Luley et al. [2].

The analyser configuration which was evaluated for this paper consisted of three units with eight reagent lines per unit for chemistry tests, and an additional ISE unit for electrolyte measurements.

\section{Materials}

\section{Quality-control materials}

The commercially available control materials used in the evaluation are specified in table 2 .

\section{Calibrators and standards}

Multianalyte calibrators obtained from Olympus Optical Co. and Merck Company were used to calibrate the respective substrate methods of both reagent suppliers. Aqueous electrolyte standards obtained from Olympus Optical Co. and Boehringer Mannheim $\mathrm{GmbH}$ were used to calibrate flame photometry and ISE measurement on the Olympus AU 5000, AU 5200 and Hitachi 747 analysers respectively. To measure linearity of chemistry procedures analyte-spiked serum materials were obtained from Sigma Chemical Company (MultiAnalyte Lintrol, Multi-Enzyme Lintrol, CK-Lintrol, Lipid-Lintrol) or produced by adding pure analyte to a serum pool (iron and bilirubin standard solutions from Sigma Chemicals).

\section{Chemistry reagents}

The reagent kits were supplied by Olympus Optical Co. in Hamburg and Merck Company in Darmstadt, Germany. A list of reagents, reagent manufacturers and methods of chemistry testing is given in table 3 . 
Table 1. Instrument specification for the AU 5200

\section{General characteristics}

Type of instrument Analytical methods

Nature of specimen Operation of the system Specimen identification Specimen carrier

Sample throughput Sample tray capacity Sampling system

Sampling volumes Sampling dispensing

Reagent type

Reagent storage

Reagent dispensor

Reagent volumes

Reagent bottle capacity

Reaction rotor

Reaction cuvettes

Reaction temperature

Reaction incubation

Reaction time

Calibrators

Optical characteristics

Light source

Photometry system

Wavelength

Light path

Photo detector

Photometric range

Sensitivity

ISE characteristics

Analytical system

Analytical items

Sample throughput

Sample type

Sample volume

Diluent volume

Data processor

Main cpu

Storage devices

On line interface

Operating system

Operator oriented software

\section{Environment}

Power consumption

Heat output

Water consumption

Waste drainage

Analyser configurations

Model

AU 5211

AU 5221

AU 5223

AU 5231

AU 5241

Fully selective discrete access multianalyser

End-point

End-point with serum blanking

Kinetic serum start

Kinetic trigger start

ISE or flame photometry

Serum, plasma, urine

With and without host computer support, batch and realtime operation

Barcode labelled primary tubes, barcode format includes codabar, 2 of 5 and code 39

Straight racks with 10 positions for patient's specimen (white), control sera (green), calibrators (yellow), water and reagent blanks (blue), emergency samples (red) and rerun samples (orange) 330 samples per hour maximally (as for 8 reagent lines per unit without ISE)

300 specimens (30 racks)

Pipettors in ISE unit (single) and each module (double) with liquid level sensor driven by stepping motors

$3-15 \mu \mathrm{l}(1 \mu \mathrm{l}$ increment)

Four tests

Liquid

Refrigerated storage $\left(4-12^{\circ} \mathrm{C}\right)$

Two independent pipettors per method

$250-500 \mu$ l total $(\mathrm{R} 1+\mathrm{R} 2)$ volume in $1 \mu \mathrm{l}$ increments

$125 \mathrm{ml}-2000 \mathrm{ml}$

Turntable with two rings of 240 cuvettes each

480 quartz glass cuvettes per unit, $6 \mathrm{~mm}$ path length

$37^{\circ} \mathrm{C}$

Dry bath with incubation liquid system

$9 \min 24 \mathrm{~s}$

Up to 5 calibrants per test parameter, linear and nonlinear calibration

Tungsten-Halogen lamp

Multiwavelength diffraction grating

Fixed array of 10 diodes: $340 \mathrm{~nm}, 380 \mathrm{~nm}, 410 \mathrm{~nm}, 480 \mathrm{~nm}, 520 \mathrm{~nm}, 540 \mathrm{~nm}, 600 \mathrm{~nm}, 660 \mathrm{~nm}$, $800 \mathrm{~nm}$

$6.0 \mathrm{~mm}$

Silicon photo cell

0.00 to 2.00 absorbance units

$0 \cdot 0001$ absorbance units

Vertical block flowcell with ion selective electrodes

Chloride, potassium, natrium

300 samples per hour

Serum, urine

$28 \mu \mathrm{l}$

$665 \mu \mathrm{l}$

Intel i8086 with i8087 coprocessor

$40 \mathrm{Mb}$ hard disk, $31 / 2$ in floppy disk

RS232 C serial interface, bidirectional data transfer

\section{CP/M 86}

Quality control; correlation correction; linear transformation $(\mathrm{Y}=\mathrm{AX}+\mathrm{B})$; test result editing: abnormal upper/lower value judgement; user defined calculated tests; user defined inter-item data check; reaction curve monitor; automatic instrument start up capability; repeat run assessment

8.0 kVA (as for AU 5231 with 3 units)

(60 A max. by $210 \mathrm{~V}$ single phase AC)

$6880 \mathrm{Kcal}$

$301 /$ hour per unit deionized water

Separately expelled: chemical and non-hazardous waste

Analyser composition (units $\times$ reagent lines)
$1 \times 16$
$2 \times 8$
$2 \times 16$
$3 \times 8$
$4 \times 8$

Assay items
(with ISE)

$16(19)$

16 (19)

32 (35)

24 (27)

32 (35)
Sample throughput/h

(with ISE)

$165(150)$

$330(300)$

$165(150)$

$330(300)$

$330(300)$ 


\section{Methods}

\section{Chemistry methods}

Both analysers were operated at $37^{\circ} \mathrm{C}$, enzyme activities were converted to corresponding activities at $25^{\circ} \mathrm{C}$. All methods employ bichromatic measurements. The chemical basis for each method on both the AU 5200 and the AU 5000 is summarized in table 2.

\section{Electrolyte measurements}

Sodium and potassium concentrations were measured by flame photometry on the AU 5000 analyser and indirect potentiometry on the AU 5200 analyser and Hitachi 747 analyser (Boehringer Mannheim, Germany). Chloride was determined by reaction with mercuric nitrate and thiocyanate (chloride reagent obtained from Greiner

\section{Table 2. Control sera used for the AU 5200 evaluation}

\begin{tabular}{|c|c|c|}
\hline Control serum & Lot No. & Manufacturer \\
\hline Decision 1 & 1101 & $\begin{array}{l}\text { Beckman Instruments } \\
\text { GmbH, Germany }\end{array}$ \\
\hline Decision 2 & 1102 & \\
\hline Decision 3 & 1103 & \\
\hline Duotrol & 5036 & Biomed, Germany \\
\hline NobiCon I & 210099 & Nobis GmbH, Germany \\
\hline NobiCon II & 220077 & \\
\hline Lyotrol N & 482870 & $\begin{array}{l}\text { BioMerieux } \mathrm{GmbH} \text {, } \\
\text { Germany }\end{array}$ \\
\hline Lyotrol P & 323760 & \\
\hline Monotrol & $629430 \mathrm{~A}$ & \\
\hline Clinitrol & $632780 \mathrm{~A}$ & \\
\hline Zymotrol & $715540 \mathrm{~A}$ & \\
\hline Qualitrol L & 326 & $\begin{array}{l}\text { Merck Darmstadt } \\
\text { GmbH, Germany }\end{array}$ \\
\hline Qualitrol N & 390 & \\
\hline Qualitrol H & 325 & \\
\hline Precinorm U & 166760 & $\begin{array}{l}\text { Boehringer Mannheim } \\
\text { GmbH, Germany }\end{array}$ \\
\hline Precipath U & 168593 & \\
\hline Moni-Trol I & LTD-218 & $\begin{array}{l}\text { Baxter Deutschland } \\
\text { GmbH, Germany }\end{array}$ \\
\hline Moni-Trol II & PTD-119 & \\
\hline Lypocheck 1 & 48901 & $\begin{array}{l}\text { BioRad Laboratories } \\
\text { GmbH, Germany }\end{array}$ \\
\hline Lyphocheck 2 & 48902 & \\
\hline Kontrollogen L & 623131 & $\begin{array}{l}\text { Behring Werke AG, } \\
\text { Germany }\end{array}$ \\
\hline Kontrollogen LP & 623218 & \\
\hline Control Serum N & O 2933 & $\begin{array}{l}\text { Hoffman-La Roche AG, } \\
\text { Germany }\end{array}$ \\
\hline Control Serum P & 3133 & \\
\hline Testpoint 1 & V05623 & $\begin{array}{l}\text { Technicon/Bayer AG, } \\
\text { Germany }\end{array}$ \\
\hline Testpoint 2 & V05602 & \\
\hline Validate $\mathrm{N}$ & 743 & $\begin{array}{l}\text { Organon Teknika } \\
\text { GmbH, Germany }\end{array}$ \\
\hline Validate A & 586 & \\
\hline Biotrol 33 Plus & 574 & Biotrol Paris, France \\
\hline Biotrol 33 Plus path. & 713 & \\
\hline Accutrol Normal & 6165 & $\begin{array}{l}\text { Sigma Chemie GmbH, } \\
\text { Germany }\end{array}$ \\
\hline Accutrol Abnormal & 6166 & \\
\hline
\end{tabular}

BioChemica in Flacht, Germany) on the AU 5000 analyser and by indirect potentiometry on the AU 5200 and Hitachi 747 analyser.

\section{Precision study}

To determine the within-run imprecision, seven different control materials and two serum pools were analysed in a series of 20 assays. The series were repeated three times and the medians of the three $\mathrm{CV}$ values were taken as the final results.

The imprecision between-days was determined on 15 different days using the seven control materials mentioned above.

\section{Assessment of accuracy}

Thirty-two commercial control materials (listed in table 2 ) were analysed in double assays on three days in both the AU 5200 and AU 5000. The medians of the measured values were compared with the assigned values of the different control materials (if available for the methodology used).

\section{Linearity study}

The linearity of each chemistry method was assessed using serum material with high analyte concentrations and 25 equidistant levels of dilution with physiological saline solution or bovine serum albumin (for cholesterol, triglyceride and bilirubin dilutions). The dilutions were prepared using a robotic dilutor system (Tecan RSP 505, Zinsser Analytik). The measured concentrations were plotted against dilution levels and the resulting graphs were inspected visually for linearity.

\section{Carry-over experiments}

Due to the construction principle that each cuvette and each mixer blade is used for one kind of test only and that the reagent lines are totally separated from one another, carry-over is restricted to sample carry-over caused by insufficient washing of subsequent cuvettes, the probe needle or the mixer blade.

Sample carry-over, due to insufficient cuvette washing, was tested by determining the activity of creatine phosphokinase during two complete cuvette wheel cycles (120 samples). All samples were taken from a serum pool with a low CPK activity of $27 \mathrm{U} / \mathrm{I}\left(25^{\circ} \mathrm{C}\right)$, except sample numbers 31 to 45 which contained a high activity of 1500 U/I. Thus, during the second cuvette wheel cycle (sample numbers 61 to 120) samples containing the low CPK activity were measured in cuvettes which had been used for the determination of the high CPK activity in the previous cuvette wheel cycle. If the cuvettes were inadequately washed, elevated CPK activity should be measured in cuvette numbers 91 to 105 .

In order to detect sample carry-over caused by the probe needle or mixer blade, groups of five samples with low CPK activity and high CPK activity were alternated 
Table 3. Test procedures and reagents used during evaluation

\begin{tabular}{|c|c|c|c|}
\hline Analyte & Method* & $\begin{array}{l}\text { Reagent } \\
\text { manufacturer }\end{array}$ & Analyser \\
\hline \multicolumn{4}{|l|}{ 1. Enzymes } \\
\hline \multirow[t]{2}{*}{ Alanine aminotransferase } & IFCG & Olympus & AU 5200 \\
\hline & IFCG & Merck & AU 5000 \\
\hline \multirow[t]{2}{*}{ Aspartate aminotransferase } & IFCG & Olympus & AU 5200 \\
\hline & IFCC & Merck & AU 5000 \\
\hline \multirow[t]{2}{*}{ Alkaline phosphatase } & DGKC & Olympus & AU 5200 \\
\hline & DGKC & Olympus & AU 5000 \\
\hline \multirow[t]{2}{*}{ Amylase } & bl. PNP-G7 & Olympus & AU 5200 \\
\hline & Cl-PNP-G7 & Merck & AU 5000 \\
\hline \multirow[t]{2}{*}{ Creatine phosphokinase } & CK-NAC, DGKC & Olympus & AU 5200 \\
\hline & GK-NAC, DGKC & Merck & AU 5000 \\
\hline \multirow[t]{2}{*}{ g-glutamyl transferase } & GCNA 'Szasz' & Olympus & AU 5200 \\
\hline & GCNa 'Szasz' & Merck & AU 5000 \\
\hline \multirow[t]{2}{*}{ Lactate dehydrogenase } & SCE & Olympus & AU 5200 \\
\hline & SGE & Merck & AU 5000 \\
\hline \multicolumn{4}{|l|}{ 2. Substrates } \\
\hline \multirow[t]{2}{*}{ Albumin } & Bromcresol green & Olympus & AU 5200 \\
\hline & Bromcresol green & Merck & AU 5000 \\
\hline \multirow[t]{2}{*}{ Bilirubin } & DCA & Olympus & AU 5200 \\
\hline & DPD & Merck & AU 5000 \\
\hline \multirow[t]{2}{*}{ Calcium } & o-Cresolphthaleine & Olympus & AU 5200 \\
\hline & o-Cresolphthaleine & Olympus & AU 5000 \\
\hline \multirow[t]{2}{*}{ Cholesterol } & CHOD-PAP & Olympus & AU 5200 \\
\hline & CHOD-PAP & Olympus & AU 5000 \\
\hline \multirow[t]{3}{*}{ Creatinine } & kinetic Jaffe & Olympus & AU 5200 \\
\hline & enzymatic PAP & Merck & AU 5200 \\
\hline & enzymatic PAP & Merck & AU 5000 \\
\hline \multirow[t]{2}{*}{ Glucose } & Hexokinase & Olympus & AU 5200 \\
\hline & Glucose dehydrogenase & Merck & AU 5000 \\
\hline \multirow[t]{2}{*}{ Phosphate } & Ammoniumheptamolybdate & Olympus & AU 5200 \\
\hline & Ammoniumheptamolybdate & Merck & AU 5000 \\
\hline \multirow[t]{2}{*}{ Iron } & Nitroso-PSAP & Olympus & AU 5200 \\
\hline & Ferrozine & Merck & AU 5000 \\
\hline \multirow[t]{2}{*}{ Total protein } & Biuret & Olympus & AU 5200 \\
\hline & Biuret & Olympus & AU 5000 \\
\hline \multirow[t]{2}{*}{ Triglycerides } & GPO-PAP & Olympus & AU 5200 \\
\hline & GPO-PAP & Olympus & AU 5000 \\
\hline \multirow[t]{2}{*}{ Urea } & GLDH & Olympus & AU 5200 \\
\hline & GLDH & Merck & AU 5000 \\
\hline Uric acid & Uricase/PAP & Olympus & AU 5200 \\
\hline & Uricase/PAP & Merck & AU 5000 \\
\hline 3. Electrolytes & & & \\
\hline Sodium & ISE indirect & & AU 5200 \\
\hline & Flame photometry & & AU 5000 \\
\hline & ISE indirect & & Hitachi \\
\hline & & & 747 \\
\hline Potassium & ISE indirect & & AU 5200 \\
\hline & Flame photometry & & AU 5000 \\
\hline & ISE indirect & & Hitachi \\
\hline & & & 747 \\
\hline Chloride & ISE indirect & & AU 5200 \\
\hline & Hg-Thiocyanate & Greiner & AU 5000 \\
\hline & ISE indirect & & Hitachi \\
\hline & & & 747 \\
\hline
\end{tabular}

${ }^{*}$ IFGG $=$ International Federation of Clincial Chemistry; DGKG = Deutsche Gesellschaft für Klinische Chemie; PNP-G7 = pNitrophenyl maltoheptaoside; CK-NAC = Creatine kinase, N-acetylcysteine activated; GCNA 'Szasz' = L-Glutamyl-3-carboxy-4nitroanilide: G. Szasz u. M, Klin. Chem. u. Klin. Biochem. 12,228 (1974); SCE = Scandinavian Committee on Enzymes; DCA = 2,4Dichloraniline-diazonium salt; DPD $=2,5$-Dichlorophenyl-diazonium salt; Nitroso-PSAP $=2$-Nitroso-5-(N-propyl-N-sulfopropylamino)-phenol; ISE = ion selective electrode. 
Table 4. Imprecision of the Olympus AU 5200 Analyser. Within-run coefficients of variation are median values of three series.

\begin{tabular}{|c|c|c|c|c|c|c|}
\hline \multirow[b]{2}{*}{ Analyte } & \multirow[b]{2}{*}{$\begin{array}{l}\text { Control } \\
\text { material }\end{array}$} & \multirow[b]{2}{*}{$\begin{array}{l}\text { Assigned } \\
\text { value }\end{array}$} & \multicolumn{2}{|c|}{$\begin{array}{l}\text { Between days } \\
(N=15 \text { days })\end{array}$} & \multicolumn{2}{|c|}{$\begin{array}{l}\text { Within-run } \\
(N=20)\end{array}$} \\
\hline & & & $\begin{array}{l}\text { Found } \\
\text { value }\end{array}$ & $\begin{array}{l}\text { Recovery } \\
\text { range }\end{array}$ & $\mathrm{CV} \%$ & $\mathrm{GV} \%$ \\
\hline $\begin{array}{l}\text { Enzymes } \\
\text { Alkaline phosphatase } \\
(\mathrm{U} / \mathrm{l})\end{array}$ & $\begin{array}{l}\text { Monitrol } 1 \\
\text { Monitrol } 2 \\
\text { Precinorm U } \\
\text { Precipath U } \\
\text { Qualitrol L } \\
\text { Qualitrol N } \\
\text { Qualitrol H }\end{array}$ & $\begin{array}{r}70 \\
293 \\
271 \\
316 \\
168 \\
273 \\
397\end{array}$ & $\begin{array}{r}76 \\
317 \\
282 \\
344 \\
142 \\
253 \\
348\end{array}$ & $\begin{array}{c}71-84 \\
304-332 \\
267-293 \\
331-357 \\
135-155 \\
245-267 \\
335-370\end{array}$ & $\begin{array}{l}4 \cdot 3 \\
2 \cdot 7 \\
2 \cdot 1 \\
2 \cdot 3 \\
3 \cdot 3 \\
2 \cdot 2 \\
2 \cdot 4\end{array}$ & $\begin{array}{l}0 \cdot 6 \\
0 \cdot 5 \\
0 \cdot 9 \\
1 \cdot 0 \\
0 \cdot 6 \\
0 \cdot 8 \\
0 \cdot 5\end{array}$ \\
\hline $\begin{array}{l}\text { Alanine aminotransferase } \\
(\mathrm{U} / \mathrm{l})\end{array}$ & $\begin{array}{l}\text { Monitrol } 1 \\
\text { Monitrol } 2 \\
\text { Precinorm U } \\
\text { Precipath U } \\
\text { Qualitrol L } \\
\text { Qualitrol N } \\
\text { Qualitrol H }\end{array}$ & $\begin{array}{r}25 \\
83 \\
30 \\
63 \\
23 \\
31 \\
104\end{array}$ & $\begin{array}{l}24 \\
73 \\
25 \\
53 \\
17 \\
22 \\
82\end{array}$ & $\begin{array}{l}23-25 \\
70-74 \\
24-25 \\
52-55 \\
16-17 \\
21-23 \\
80-83\end{array}$ & $\begin{array}{l}2 \cdot 4 \\
1 \cdot 5 \\
2 \cdot 1 \\
1 \cdot 5 \\
2 \cdot 5 \\
3 \cdot 1 \\
1 \cdot 3\end{array}$ & $\begin{array}{l}1 \cdot 6 \\
0 \cdot 5 \\
1 \cdot 8 \\
0 \cdot 4 \\
0 \cdot 1 \\
2 \cdot 2 \\
0.8\end{array}$ \\
\hline $\begin{array}{l}\text { Amylase } \\
(\mathrm{U} / \mathrm{l})\end{array}$ & $\begin{array}{l}\text { Monitrol 1 } \\
\text { Monitrol } 2 \\
\text { Precinorm U } \\
\text { Precipath U } \\
\text { Qualitrol L } \\
\text { Qualitrol N } \\
\text { Qualitrol H }\end{array}$ & & $\begin{array}{r}41 \\
149 \\
63 \\
120 \\
41 \\
59 \\
221\end{array}$ & $\begin{array}{c}36-48 \\
133-156 \\
62-65 \\
116-124 \\
38-44 \\
58-61 \\
215-227\end{array}$ & $\begin{array}{r}10 \cdot 2 \\
3 \cdot 1 \\
1 \cdot 3 \\
1 \cdot 5 \\
2 \cdot 0 \\
3 \cdot 8 \\
1 \cdot 4\end{array}$ & $\begin{array}{l}2 \cdot 0 \\
0 \cdot 7 \\
1 \cdot 2 \\
0 \cdot 8 \\
1 \cdot 4 \\
0 \cdot 8 \\
0 \cdot 5\end{array}$ \\
\hline $\begin{array}{l}\text { Aspartate aminotransferase } \\
(\mathrm{U} / \mathrm{l})\end{array}$ & $\begin{array}{l}\text { Monitrol 1 } \\
\text { Monitrol } 2 \\
\text { Precinorm U } \\
\text { Precipath U } \\
\text { Qualitrol L } \\
\text { Qualitrol N } \\
\text { Qualitrol H }\end{array}$ & $\begin{array}{l}32 \\
76 \\
26 \\
60 \\
22 \\
45 \\
99\end{array}$ & $\begin{array}{l}32 \\
73 \\
22 \\
52 \\
18 \\
38 \\
85\end{array}$ & $\begin{array}{l}28-34 \\
67-74 \\
21-23 \\
49-53 \\
17-21 \\
37-39 \\
81-87\end{array}$ & $\begin{array}{l}4 \cdot 6 \\
2 \cdot 4 \\
2 \cdot 3 \\
2 \cdot 2 \\
4 \cdot 0 \\
1 \cdot 4 \\
1 \cdot 9\end{array}$ & $\begin{array}{l}1 \cdot 6 \\
0 \cdot 6 \\
1 \cdot 0 \\
0 \cdot 8 \\
2 \cdot 6 \\
1 \cdot 8 \\
0 \cdot 6\end{array}$ \\
\hline $\begin{array}{l}\text { Greatine phosphokinase } \\
(\mathrm{U} / \mathrm{l})\end{array}$ & $\begin{array}{l}\text { Monitrol 1 } \\
\text { Monitrol } 2 \\
\text { Precinorm U } \\
\text { Precipath U } \\
\text { Qualitrol L } \\
\text { Qualitrol N } \\
\text { Qualitrol H }\end{array}$ & $\begin{array}{r}56 \\
147 \\
114 \\
207 \\
44 \\
90 \\
200\end{array}$ & $\begin{array}{r}56 \\
150 \\
95 \\
169 \\
37 \\
81 \\
145\end{array}$ & $\begin{array}{c}44-62 \\
121-179 \\
80-113 \\
144-185 \\
23-48 \\
71-93 \\
88-189\end{array}$ & $\begin{array}{r}10 \cdot 2 \\
9 \cdot 5 \\
7 \cdot 9 \\
7 \cdot 3 \\
15 \cdot 7 \\
6 \cdot 1 \\
14 \cdot 2\end{array}$ & $\begin{array}{l}1 \cdot 5 \\
0 \cdot 8 \\
0 \cdot 7 \\
1 \cdot 1 \\
2 \cdot 2 \\
0 \cdot 6 \\
0 \cdot 7\end{array}$ \\
\hline $\begin{array}{l}\text { g-Glutamyltransferase } \\
(\mathrm{U} / \mathrm{l})\end{array}$ & $\begin{array}{l}\text { Monitrol 1 } \\
\text { Monitrol } 2 \\
\text { Precinorm U } \\
\text { Precipath U } \\
\text { Qualitrol L } \\
\text { Qualitrol N } \\
\text { Qualitrol H }\end{array}$ & $\begin{array}{r}20 \\
46 \\
38 \\
107 \\
15 \\
19 \\
82\end{array}$ & $\begin{array}{r}19 \\
43 \\
36 \\
107 \\
14 \\
19 \\
77\end{array}$ & $\begin{array}{c}19-20 \\
43-45 \\
35-38 \\
103-109 \\
14-15 \\
18-20 \\
75-79\end{array}$ & $\begin{array}{l}2 \cdot 6 \\
1 \cdot 5 \\
2 \cdot 2 \\
1 \cdot 3 \\
3 \cdot 0 \\
2 \cdot 3 \\
1 \cdot 4\end{array}$ & $\begin{array}{l}1 \cdot 6 \\
0 \cdot 7 \\
1 \cdot 6 \\
0 \cdot 7 \\
3 \cdot 3 \\
2 \cdot 3 \\
0 \cdot 7\end{array}$ \\
\hline $\begin{array}{l}\text { Lactate dehydrogenase } \\
(\mathrm{U} / \mathrm{l})\end{array}$ & $\begin{array}{l}\text { Monitrol 1 } \\
\text { Monitrol } 2 \\
\text { Precinorm U } \\
\text { Precipath U } \\
\text { Qualitrol L } \\
\text { Qualitrol N } \\
\text { Qualitrol H }\end{array}$ & $\begin{array}{l}196 \\
319 \\
175 \\
266 \\
129 \\
306 \\
548\end{array}$ & $\begin{array}{l}193 \\
308 \\
148 \\
229 \\
110 \\
251 \\
447\end{array}$ & $\begin{array}{l}178-204 \\
294-324 \\
135-156 \\
217-242 \\
104-121 \\
239-259 \\
426-461\end{array}$ & $\begin{array}{l}3 \cdot 1 \\
2 \cdot 5 \\
3 \cdot 2 \\
2 \cdot 7 \\
3 \cdot 0 \\
2 \cdot 5 \\
2 \cdot 2\end{array}$ & $\begin{array}{l}1 \cdot 0 \\
0 \cdot 5 \\
1 \cdot 3 \\
0 \cdot 9 \\
1 \cdot 5 \\
0 \cdot 6 \\
0 \cdot 4\end{array}$ \\
\hline $\begin{array}{l}\text { Substrates } \\
\text { Albumin } \\
(\mathrm{g} / \mathrm{dl})\end{array}$ & $\begin{array}{l}\text { Monitrol } 1 \\
\text { Monitrol } 2 \\
\text { Precinorm U } \\
\text { Precipath U } \\
\text { Qualitrol L } \\
\text { Qualitrol N } \\
\text { Qualitrol H }\end{array}$ & $\begin{array}{l}4 \cdot 3 \\
3 \cdot 3 \\
3 \cdot 5 \\
3 \cdot 3 \\
2 \cdot 1 \\
4 \cdot 7 \\
4 \cdot 1\end{array}$ & $\begin{array}{l}3 \cdot 5 \\
2 \cdot 5 \\
2 \cdot 6 \\
2 \cdot 5 \\
1 \cdot 8 \\
4 \cdot 2 \\
3 \cdot 9\end{array}$ & $\begin{array}{l}3 \cdot 4-3 \cdot 6 \\
2 \cdot 4-2 \cdot 6 \\
2 \cdot 5-2 \cdot 8 \\
2 \cdot 3-2 \cdot 6 \\
1 \cdot 7-1 \cdot 9 \\
4 \cdot 1-4 \cdot 3 \\
3 \cdot 8-4 \cdot 1\end{array}$ & $\begin{array}{l}1 \cdot 7 \\
1 \cdot 7 \\
2 \cdot 3 \\
2 \cdot 6 \\
2 \cdot 5 \\
1 \cdot 4 \\
1 \cdot 9\end{array}$ & $\begin{array}{l}1 \cdot 4 \\
1 \cdot 7 \\
1 \cdot 7 \\
1 \cdot 2 \\
2 \cdot 2 \\
1 \cdot 4 \\
1 \cdot 1\end{array}$ \\
\hline
\end{tabular}


Table 4 (continued).

\begin{tabular}{|c|c|c|c|c|c|c|}
\hline \multirow[b]{2}{*}{ Analyte } & \multirow[b]{2}{*}{$\begin{array}{l}\text { Control } \\
\text { material }\end{array}$} & \multirow[b]{2}{*}{$\begin{array}{l}\text { Assigned } \\
\text { value }\end{array}$} & \multicolumn{2}{|c|}{$\begin{array}{l}\text { Between days } \\
(N=15 \text { days })\end{array}$} & \multicolumn{2}{|c|}{$\begin{array}{l}\text { Within-run } \\
(N=20)\end{array}$} \\
\hline & & & $\begin{array}{l}\text { Found } \\
\text { value }\end{array}$ & $\begin{array}{l}\text { Recovery } \\
\text { range }\end{array}$ & $\mathrm{CV} \%$ & CV \% \\
\hline $\begin{array}{l}\text { Total bilirubin } \\
(\mathrm{mg} / \mathrm{dl})\end{array}$ & $\begin{array}{l}\text { Monitrol 1 } \\
\text { Monitrol } 2 \\
\text { Precinorm U } \\
\text { Precipath U } \\
\text { Qualitrol L } \\
\text { Qualitrol N } \\
\text { Qualitrol H }\end{array}$ & $\begin{array}{l}1 \cdot 3 \\
4 \cdot 6 \\
2 \cdot 1 \\
4 \cdot 4 \\
1 \cdot 5 \\
1 \cdot 2 \\
4 \cdot 5\end{array}$ & $\begin{array}{l}1 \cdot 3 \\
4 \cdot 6 \\
2 \cdot 0 \\
4 \cdot 5 \\
1 \cdot 6 \\
1 \cdot 3 \\
5 \cdot 0\end{array}$ & $\begin{array}{l}1 \cdot 1-1 \cdot 3 \\
4 \cdot 5-5 \cdot 0 \\
1 \cdot 7-2 \cdot 1 \\
4 \cdot 0-4 \cdot 8 \\
1 \cdot 5-1 \cdot 6 \\
1 \cdot 1-1 \cdot 4 \\
4 \cdot 9-5 \cdot 2\end{array}$ & $\begin{array}{l}4 \cdot 6 \\
2 \cdot 7 \\
5 \cdot 5 \\
4 \cdot 1 \\
2 \cdot 5 \\
5 \cdot 2 \\
1 \cdot 7\end{array}$ & $\begin{array}{l}1 \cdot 7 \\
1 \cdot 5 \\
2 \cdot 3 \\
1 \cdot 5 \\
1 \cdot 4 \\
2 \cdot 9 \\
1 \cdot 8\end{array}$ \\
\hline $\begin{array}{l}\text { Calcium } \\
(\mathrm{mmol} / \mathrm{l})\end{array}$ & $\begin{array}{l}\text { Monitrol } 1 \\
\text { Monitrol } 2 \\
\text { Precinorm U } \\
\text { Precipath U } \\
\text { Qualitrol L } \\
\text { Qualitrol N } \\
\text { Qualitrol H }\end{array}$ & $\begin{array}{l}2 \cdot 3 \\
3 \cdot 2 \\
2 \cdot 6 \\
3 \cdot 5 \\
1 \cdot 3 \\
2 \cdot 8 \\
3 \cdot 1\end{array}$ & $\begin{array}{l}2 \cdot 3 \\
3 \cdot 2 \\
2 \cdot 7 \\
3 \cdot 5 \\
1 \cdot 4 \\
2 \cdot 7 \\
3 \cdot 1\end{array}$ & $\begin{array}{l}2 \cdot 3-2 \cdot 3 \\
3 \cdot 1-3 \cdot 2 \\
2 \cdot 6-2 \cdot 7 \\
3 \cdot 4-3 \cdot 6 \\
1 \cdot 3-1 \cdot 4 \\
2 \cdot 7-2 \cdot 9 \\
3 \cdot 1-3 \cdot 2\end{array}$ & $\begin{array}{l}1 \cdot 0 \\
1 \cdot 2 \\
1 \cdot 3 \\
1 \cdot 4 \\
1 \cdot 5 \\
2 \cdot 3 \\
1 \cdot 2\end{array}$ & $\begin{array}{l}0 \cdot 7 \\
0 \cdot 7 \\
1 \cdot 0 \\
0 \cdot 5 \\
0 \cdot 9 \\
0 \cdot 7 \\
0 \cdot 8\end{array}$ \\
\hline $\begin{array}{l}\text { Cholesterol } \\
(\mathrm{mg} / \mathrm{dl})\end{array}$ & $\begin{array}{l}\text { Monitrol 1 } \\
\text { Monitrol } 2 \\
\text { Percinorm U } \\
\text { Precipath U } \\
\text { Qualitrol L } \\
\text { Qualitrol N } \\
\text { Qualitrol H }\end{array}$ & $\begin{array}{l}184 \\
124 \\
106 \\
125 \\
117 \\
114 \\
233\end{array}$ & $\begin{array}{r}176 \\
114 \\
95 \\
115 \\
107 \\
107 \\
218\end{array}$ & $\begin{array}{c}172-184 \\
112-118 \\
92-98 \\
113-120 \\
102-112 \\
104-110 \\
213-224\end{array}$ & $\begin{array}{l}1 \cdot 7 \\
1 \cdot 3 \\
1 \cdot 4 \\
1 \cdot 6 \\
1 \cdot 8 \\
1 \cdot 4 \\
1 \cdot 3\end{array}$ & $\begin{array}{l}0 \cdot 6 \\
0 \cdot 6 \\
0 \cdot 7 \\
0 \cdot 7 \\
0 \cdot 5 \\
0 \cdot 7 \\
0 \cdot 5\end{array}$ \\
\hline $\begin{array}{l}\text { Creatinine Jaffe } \\
(\mathrm{mg} / \mathrm{dl})\end{array}$ & $\begin{array}{l}\text { Monitrol 1 } \\
\text { Monitrol } 2 \\
\text { Precinorm U } \\
\text { Precipath U } \\
\text { Qualitrol L } \\
\text { Qualitrol N } \\
\text { Qualitrol H }\end{array}$ & $\begin{array}{l}1 \cdot 2 \\
5 \cdot 0 \\
1 \cdot 7 \\
3 \cdot 3 \\
1 \cdot 2 \\
1 \cdot 0 \\
7 \cdot 1\end{array}$ & $\begin{array}{l}1 \cdot 1 \\
5 \cdot 1 \\
1 \cdot 9 \\
3 \cdot 5 \\
1 \cdot 1 \\
0 \cdot 9 \\
6 \cdot 6\end{array}$ & $\begin{array}{l}1 \cdot 0-1 \cdot 2 \\
4 \cdot 9-5 \cdot 3 \\
1 \cdot 8-2 \cdot 3 \\
3 \cdot 2-3 \cdot 7 \\
1 \cdot 0-1 \cdot 2 \\
0 \cdot 8-1 \cdot 0 \\
6 \cdot 4-6 \cdot 7\end{array}$ & $\begin{array}{l}4 \cdot 1 \\
1 \cdot 6 \\
6 \cdot 2 \\
2 \cdot 7 \\
5 \cdot 1 \\
6 \cdot 1 \\
1 \cdot 3\end{array}$ & $\begin{array}{l}3 \cdot 1 \\
1 \cdot 5 \\
3 \cdot 2 \\
1 \cdot 9 \\
4 \cdot 7 \\
4 \cdot 0 \\
1 \cdot 4\end{array}$ \\
\hline $\begin{array}{l}\text { Creatinine enz. } \\
(\mathrm{mg} / \mathrm{dl})\end{array}$ & $\begin{array}{l}\text { Monitrol } 1 \\
\text { Monitrol } 2 \\
\text { Precinorm U } \\
\text { Precipath U } \\
\text { Qualitrol L } \\
\text { Qualitrol N } \\
\text { Qualitrol H }\end{array}$ & $\begin{array}{l}1 \cdot 1 \\
5 \cdot 7 \\
1 \cdot 9 \\
3 \cdot 9 \\
1 \cdot 2 \\
0 \cdot 8 \\
7 \cdot 2\end{array}$ & $\begin{array}{l}1 \cdot 1 \\
6 \cdot 2 \\
1 \cdot 9 \\
4 \cdot 1 \\
1 \cdot 3 \\
0 \cdot 8 \\
8 \cdot 1\end{array}$ & $\begin{array}{l}1 \cdot 1-1 \cdot 2 \\
5 \cdot 6-6 \cdot 4 \\
1 \cdot 4-2 \cdot 0 \\
3 \cdot 7-4 \cdot 2 \\
0 \cdot 9-1 \cdot 4 \\
0 \cdot 8-0 \cdot 9 \\
7 \cdot 7-8 \cdot 4\end{array}$ & $\begin{array}{l}1 \cdot 1 \\
2 \cdot 6 \\
6 \cdot 9 \\
3 \cdot 2 \\
8 \cdot 9 \\
1 \cdot 8 \\
2 \cdot 0\end{array}$ & $\begin{array}{l}1 \cdot 5 \\
1 \cdot 0 \\
1 \cdot 5 \\
0 \cdot 8 \\
1 \cdot 5 \\
1 \cdot 7 \\
0 \cdot 5\end{array}$ \\
\hline $\begin{array}{l}\text { Glucose } \\
(\mathrm{mg} / \mathrm{dl})\end{array}$ & $\begin{array}{l}\text { Monitrol } 1 \\
\text { Monitrol } 2 \\
\text { Precinorm U } \\
\text { Precipath U } \\
\text { Qualitrol L } \\
\text { Qualitrol N } \\
\text { Qualitrol H }\end{array}$ & $\begin{array}{r}75 \\
245 \\
114 \\
236 \\
41 \\
95 \\
206\end{array}$ & $\begin{array}{r}88 \\
254 \\
120 \\
249 \\
45 \\
102 \\
207\end{array}$ & $\begin{array}{c}84-91 \\
239-269 \\
114-123 \\
242-257 \\
40-44 \\
98-109 \\
200-213\end{array}$ & $\begin{array}{l}2 \cdot 8 \\
4 \cdot 0 \\
1 \cdot 6 \\
1 \cdot 6 \\
5 \cdot 3 \\
2 \cdot 4 \\
1 \cdot 7\end{array}$ & $\begin{array}{l}0 \cdot 6 \\
0 \cdot 7 \\
1 \cdot 0 \\
0 \cdot 6 \\
1 \cdot 4 \\
0 \cdot 7 \\
0 \cdot 6\end{array}$ \\
\hline $\begin{array}{l}\text { Inorganic phosphate } \\
(\mathrm{mg} / \mathrm{dl})\end{array}$ & $\begin{array}{l}\text { Monitrol 1 } \\
\text { Monitrol } 2 \\
\text { Precinorm U } \\
\text { Precipath U } \\
\text { Qualitrol L } \\
\text { Qualitrol N } \\
\text { Qualitrol H }\end{array}$ & $\begin{array}{l}3 \cdot 4 \\
6 \cdot 9 \\
5 \cdot 2 \\
6 \cdot 0 \\
4 \cdot 0 \\
2 \cdot 6 \\
8 \cdot 1\end{array}$ & $\begin{array}{l}3 \cdot 6 \\
7 \cdot 2 \\
5 \cdot 5 \\
6 \cdot 3 \\
4 \cdot 1 \\
2 \cdot 3 \\
8 \cdot 8\end{array}$ & $\begin{array}{l}3 \cdot 5-3.7 \\
6 \cdot 9-7 \cdot 4 \\
5 \cdot 2-5 \cdot 6 \\
6 \cdot 0-6 \cdot 5 \\
3 \cdot 9-4 \cdot 3 \\
2 \cdot 1-2 \cdot 3 \\
8 \cdot 5-9 \cdot 1\end{array}$ & $\begin{array}{l}1 \cdot 3 \\
2 \cdot 0 \\
2 \cdot 1 \\
2 \cdot 0 \\
2 \cdot 1 \\
2 \cdot 9 \\
2 \cdot 1\end{array}$ & $\begin{array}{l}1 \cdot 8 \\
0 \cdot 5 \\
1 \cdot 0 \\
0 \cdot 8 \\
1 \cdot 8 \\
1 \cdot 5 \\
0 \cdot 6\end{array}$ \\
\hline $\begin{array}{l}\text { Iron } \\
\text { (ug/dl) }\end{array}$ & $\begin{array}{l}\text { Monitrol 1 } \\
\text { Monitrol } 2 \\
\text { Precinorm U } \\
\text { Precipath U } \\
\text { Qualitrol L } \\
\text { Qualitrol N } \\
\text { Qualitrol H }\end{array}$ & $\begin{array}{r}108 \\
190 \\
120 \\
136 \\
84 \\
211 \\
181\end{array}$ & $\begin{array}{r}101 \\
214 \\
115 \\
129 \\
84 \\
190 \\
175\end{array}$ & $\begin{array}{c}97-109 \\
205-239 \\
112-120 \\
126-132 \\
75-95 \\
184-207 \\
169-185\end{array}$ & $\begin{array}{l}2 \cdot 7 \\
4 \cdot 1 \\
1 \cdot 8 \\
1 \cdot 5 \\
6 \cdot 4 \\
3 \cdot 1 \\
2 \cdot 3\end{array}$ & $\begin{array}{l}2 \cdot 5 \\
0 \cdot 7 \\
1 \cdot 2 \\
1 \cdot 0 \\
2 \cdot 3 \\
0 \cdot 6 \\
1 \cdot 1\end{array}$ \\
\hline
\end{tabular}


Table 4 (continued).

\begin{tabular}{|c|c|c|c|c|c|c|}
\hline \multirow[b]{2}{*}{ Analyte } & \multirow[b]{2}{*}{$\begin{array}{l}\text { Control } \\
\text { material }\end{array}$} & \multirow[b]{2}{*}{$\begin{array}{l}\text { Assigned } \\
\text { value }\end{array}$} & \multicolumn{2}{|c|}{$\begin{array}{l}\text { Between days } \\
(N=15 \text { days })\end{array}$} & \multicolumn{2}{|c|}{$\begin{array}{l}\text { Within-run } \\
(N=20)\end{array}$} \\
\hline & & & $\begin{array}{l}\text { Found } \\
\text { value }\end{array}$ & $\begin{array}{l}\text { Recovery } \\
\text { range }\end{array}$ & $\mathrm{CV} \%$ & CV \% \\
\hline $\begin{array}{l}\text { Total protein } \\
(\mathrm{g} / \mathrm{dl})\end{array}$ & $\begin{array}{l}\text { Monitrol } 1 \\
\text { Monitrol } 2 \\
\text { Precinorm U } \\
\text { Precipath U } \\
\text { Qualitrol L } \\
\text { Qualitrol N } \\
\text { Qualitrol H }\end{array}$ & $\begin{array}{l}6 \cdot 8 \\
5 \cdot 1 \\
5 \cdot 0 \\
4 \cdot 9 \\
4 \cdot 7 \\
8 \cdot 7 \\
8 \cdot 9\end{array}$ & $\begin{array}{l}7 \cdot 0 \\
5 \cdot 1 \\
5 \cdot 0 \\
4 \cdot 9 \\
4 \cdot 7 \\
8 \cdot 7 \\
8 \cdot 9\end{array}$ & $\begin{array}{l}6 \cdot 8-7 \cdot 2 \\
5 \cdot 0-5 \cdot 3 \\
4 \cdot 9-5 \cdot 1 \\
4 \cdot 8-5 \cdot 0 \\
4 \cdot 5-4 \cdot 8 \\
7 \cdot 8-8 \cdot 1 \\
8 \cdot 9-9 \cdot 3\end{array}$ & $\begin{array}{l}1 \cdot 4 \\
1 \cdot 4 \\
1 \cdot 2 \\
1 \cdot 2 \\
1 \cdot 9 \\
1 \cdot 2 \\
1 \cdot 0\end{array}$ & $\begin{array}{l}0 \cdot 6 \\
0 \cdot 9 \\
1 \cdot 0 \\
0 \cdot 8 \\
1 \cdot 0 \\
0 \cdot 5 \\
0 \cdot 5\end{array}$ \\
\hline $\begin{array}{l}\text { Triglyzerides } \\
(\mathrm{mg} / \mathrm{dl})\end{array}$ & $\begin{array}{l}\text { Monitrol } 1 \\
\text { Monitrol } 2 \\
\text { Precinorm U } \\
\text { Precipath U } \\
\text { Qualitrol L } \\
\text { Qualitrol N } \\
\text { Qualitrol H }\end{array}$ & $\begin{array}{r}88 \\
184 \\
105 \\
136 \\
93 \\
128 \\
251\end{array}$ & $\begin{array}{r}80 \\
167 \\
90 \\
114 \\
79 \\
107 \\
209\end{array}$ & $\begin{array}{c}77-82 \\
160-173 \\
86-93 \\
103-118 \\
76-81 \\
102-109 \\
202-215\end{array}$ & $\begin{array}{l}1 \cdot 6 \\
1 \cdot 6 \\
1 \cdot 8 \\
2 \cdot 6 \\
1 \cdot 6 \\
1 \cdot 7 \\
1 \cdot 7\end{array}$ & $\begin{array}{l}0 \cdot 9 \\
0 \cdot 9 \\
0 \cdot 9 \\
0 \cdot 9 \\
1 \cdot 2 \\
0 \cdot 5 \\
0 \cdot 4\end{array}$ \\
\hline $\begin{array}{l}\text { Urea } \\
(\mathrm{mg} / \mathrm{dl})\end{array}$ & $\begin{array}{l}\text { Monitrol 1 } \\
\text { Monitrol } 2 \\
\text { Precinorm U } \\
\text { Precipath U } \\
\text { Qualitrol L } \\
\text { Qualitrol N } \\
\text { Qualitrol H }\end{array}$ & $\begin{array}{r}32 \\
108 \\
57 \\
151 \\
16 \\
38 \\
168\end{array}$ & $\begin{array}{r}31 \\
109 \\
56 \\
157 \\
15 \\
37 \\
174\end{array}$ & $\begin{array}{c}30-33 \\
106-114 \\
55-59 \\
152-161 \\
14-16 \\
35-39 \\
169-179\end{array}$ & $\begin{array}{l}2 \cdot 5 \\
1 \cdot 9 \\
2 \cdot 1 \\
1 \cdot 9 \\
3 \cdot 5 \\
2 \cdot 8 \\
1 \cdot 6\end{array}$ & $\begin{array}{l}1 \cdot 9 \\
2 \cdot 4 \\
1 \cdot 8 \\
2 \cdot 2 \\
3 \cdot 3 \\
1 \cdot 4 \\
1 \cdot 1\end{array}$ \\
\hline $\begin{array}{l}\text { Uric acid } \\
(\mathrm{mg} / \mathrm{dl})\end{array}$ & $\begin{array}{l}\text { Monitrol } 1 \\
\text { Monitrol } 2 \\
\text { Precinorm U } \\
\text { Precipath U } \\
\text { Qualitrol L } \\
\text { Qualitrol N } \\
\text { Qualitrol H }\end{array}$ & $\begin{array}{r}5 \cdot 3 \\
8 \cdot 3 \\
5 \cdot 9 \\
10 \cdot 2 \\
3 \cdot 6 \\
6 \cdot 9 \\
10 \cdot 2\end{array}$ & $\begin{array}{r}5 \cdot 2 \\
8 \cdot 2 \\
4 \cdot 9 \\
10 \cdot 4 \\
3 \cdot 3 \\
7 \cdot 0 \\
10 \cdot 0\end{array}$ & $\begin{array}{c}5 \cdot 0-5 \cdot 4 \\
7 \cdot 6-8 \cdot 6 \\
4 \cdot 8-5 \cdot 2 \\
10 \cdot 1-10 \cdot 7 \\
3 \cdot 1-3 \cdot 4 \\
6 \cdot 7-7 \cdot 2 \\
9 \cdot 5-10 \cdot 3\end{array}$ & $\begin{array}{l}2 \cdot 0 \\
2 \cdot 4 \\
2 \cdot 1 \\
1 \cdot 7 \\
1 \cdot 9 \\
1 \cdot 8 \\
2 \cdot 0\end{array}$ & $\begin{array}{l}1 \cdot 2 \\
0 \cdot 7 \\
1 \cdot 2 \\
1 \cdot 1 \\
1 \cdot 7 \\
1 \cdot 0 \\
1 \cdot 6\end{array}$ \\
\hline $\begin{array}{l}\text { Electrolytes } \\
\text { Sodium } \\
(\mathrm{mmol} / \mathrm{l})\end{array}$ & $\begin{array}{l}\text { Monitrol } 1 \\
\text { Monitrol } 2 \\
\text { Precinorm U } \\
\text { Precipath U } \\
\text { Qualitrol L } \\
\text { Qualitrol N } \\
\text { Qualitrol H }\end{array}$ & $\begin{array}{l}139 \\
111 \\
123 \\
137 \\
116 \\
154 \\
161\end{array}$ & $\begin{array}{l}140 \\
112 \\
124 \\
141 \\
120 \\
155 \\
164\end{array}$ & $\begin{array}{l}136-145 \\
108-117 \\
118-129 \\
137-147 \\
114-122 \\
150-159 \\
159-167\end{array}$ & $\begin{array}{l}2 \cdot 5 \\
2 \cdot 3 \\
2 \cdot 2 \\
2 \cdot 6 \\
2 \cdot 3 \\
2 \cdot 4 \\
2 \cdot 3\end{array}$ & $\begin{array}{l}0 \cdot 3 \\
0 \cdot 9 \\
0 \cdot 7 \\
0 \cdot 4 \\
0 \cdot 4 \\
0 \cdot 3 \\
0 \cdot 3\end{array}$ \\
\hline $\begin{array}{l}\text { Potassium } \\
(\mathrm{mmol} / \mathrm{l})\end{array}$ & $\begin{array}{l}\text { Monitrol 1 } \\
\text { Monitrol } 2 \\
\text { Precinorm U } \\
\text { Precipath U } \\
\text { Qualitrol L } \\
\text { Qualitrol N } \\
\text { Qualitrol H }\end{array}$ & $\begin{array}{l}4 \cdot 40 \\
6 \cdot 65 \\
4 \cdot 64 \\
6 \cdot 91 \\
2 \cdot 28 \\
5 \cdot 25 \\
6 \cdot 50\end{array}$ & $\begin{array}{l}4 \cdot 41 \\
6 \cdot 81 \\
4 \cdot 73 \\
7 \cdot 06 \\
2 \cdot 32 \\
5 \cdot 45 \\
6 \cdot 69\end{array}$ & $\begin{array}{l}4 \cdot 30-4 \cdot 60 \\
6 \cdot 60-7 \cdot 10 \\
4 \cdot 70-4 \cdot 90 \\
6 \cdot 90-7 \cdot 30 \\
2 \cdot 20-2 \cdot 40 \\
5 \cdot 20-5 \cdot 60 \\
6 \cdot 40-6 \cdot 80\end{array}$ & $\begin{array}{l}1 \cdot 8 \\
2 \cdot 3 \\
1 \cdot 5 \\
1 \cdot 7 \\
1 \cdot 7 \\
1 \cdot 9 \\
2 \cdot 0\end{array}$ & $\begin{array}{l}0 \cdot 6 \\
1 \cdot 5 \\
0 \cdot 8 \\
0 \cdot 5 \\
1 \cdot 2 \\
0 \cdot 5 \\
0 \cdot 4\end{array}$ \\
\hline $\begin{array}{l}\text { Chloride } \\
(\mathrm{mmol} / \mathrm{l})\end{array}$ & $\begin{array}{l}\text { Monitrol } 1 \\
\text { Monitrol } 2 \\
\text { Precinorm U } \\
\text { Precipath U } \\
\text { Qualitrol L } \\
\text { Qualitrol N } \\
\text { Qualitrol H }\end{array}$ & $\begin{array}{r}109 \\
90 \\
77 \\
119 \\
84 \\
94 \\
120\end{array}$ & $\begin{array}{r}110 \\
90 \\
81 \\
124 \\
86 \\
95 \\
118\end{array}$ & $\begin{array}{c}107-115 \\
89-93 \\
78-84 \\
121-130 \\
82-90 \\
93-100 \\
114-119\end{array}$ & $\begin{array}{l}1.9 \\
1.7 \\
1.6 \\
1.9 \\
1.5 \\
1.7 \\
1.6\end{array}$ & $\begin{array}{l}0 \cdot 4 \\
0 \cdot 5 \\
0 \cdot 5 \\
0 \cdot 4 \\
0 \cdot 5 \\
0 \cdot 4 \\
0 \cdot 4\end{array}$ \\
\hline
\end{tabular}

several times. If carry-over had occurred, samples immediately following the groups with high activity should have shown elevated activities.

\section{Correlation study}

Approximately 250 fresh human sera from daily routine samples were analysed simultaneously in the AU 5200 and in the AU 5000. In addition, sodium, potassium and chloride concentrations in the same samples were measured in a Hitachi 747 analyser equipped with a ISE unit. Care was taken to include pathological analyte levels.

\section{Assessment of drift effects}

Drift effects were studied using seven commercial control sera. The sera were dissolved before starting the drift 
experiment and kept at $4^{\circ} \mathrm{C}$ until use. For determination of alkaline phosphatase, creatine phosphokinase and bilirubin the sera were freshly reconstituted every hour. Five measurements of each control serum were carried out every $60 \mathrm{~min}$ for $9 \mathrm{~h}$. Prior to starting a series of

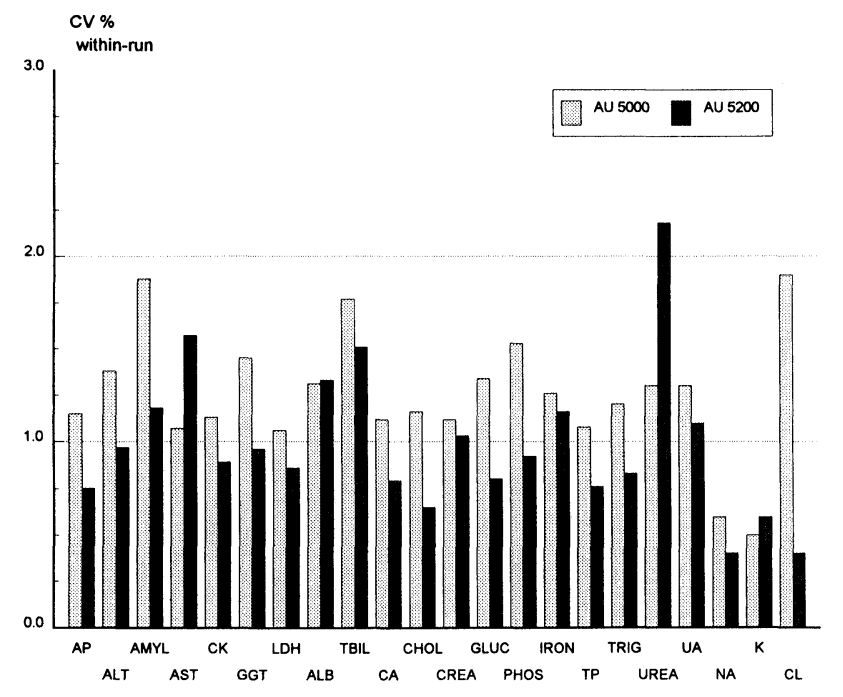

Figure 1 (a). Imprecision within-run on both the AU 5200 and the comparison instrument. The bars plotted in this figure represent median $C V$ values of the data in table 4. measurements the reagent lines were flushed with fresh reagent.

In order to detect short-term variations or sudden changes, a second experiment was conducted. Chemistry

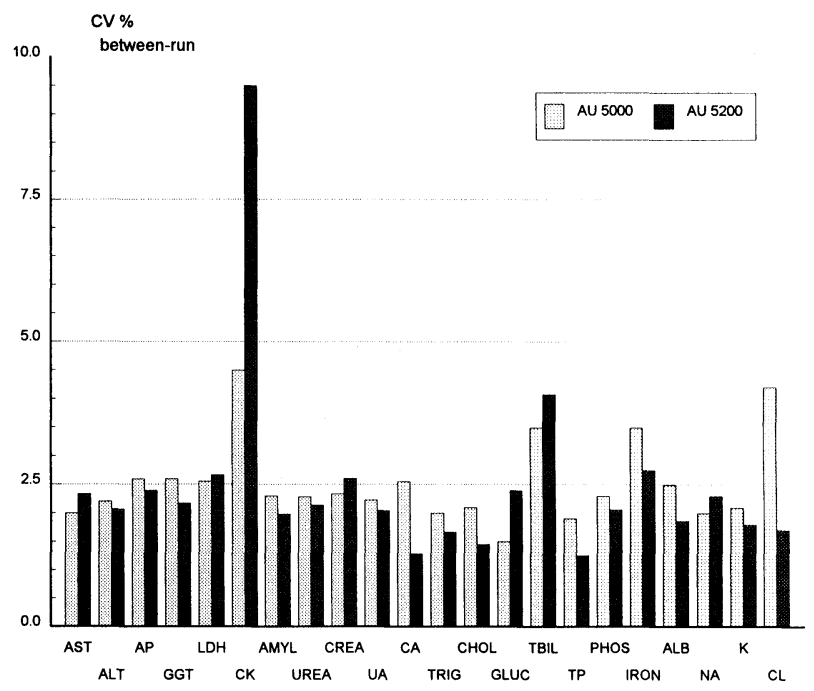

Figure 1 (b). Imprecision between-run on both the AU 5200 and the comparison instrument. The bars plotted in this figure represent median $C V$ values of the data in table 4.

Table 5. Recovery of assigned values in quality-control materials. The minimum and maximum of the assigned values are shown for all tested paramaters. The median, 10th, 25th, 75th and 90th percentiles of the found values are expressed as percentages of the assigned values.

\begin{tabular}{|c|c|c|c|c|c|c|c|c|}
\hline \multirow[b]{2}{*}{ Analyte } & \multirow[b]{2}{*}{$N$} & \multicolumn{2}{|c|}{ Assigned } & \multicolumn{5}{|c|}{ Found $(\%)$} \\
\hline & & Minimum & Maximum & Median & 10th P. & 25th P. & 75th P. & 90th P. \\
\hline \multicolumn{9}{|l|}{ Enzymes } \\
\hline Alkaline phosphatase & 22 & 47 & 423 & 103 & 85 & 88 & 107 & 112 \\
\hline Alanine aminotransferase & 22 & 16 & 104 & 85 & 78 & 83 & 88 & 94 \\
\hline Amylase & 11 & 20 & 173 & 95 & 91 & 92 & 100 & 111 \\
\hline Aspartate aminotransferase & 22 & 10 & 99 & 87 & 82 & 84 & 94 & 104 \\
\hline Creatine phosphokinase & 22 & 22 & 229 & 85 & 74 & 82 & 96 & 100 \\
\hline g-Glutamyl-transferase & 22 & 10 & 110 & 101 & 94 & 98 & 106 & 110 \\
\hline Lactate dehydrogenase & 22 & 123 & 548 & 92 & 86 & 87 & 99 & 102 \\
\hline \multicolumn{9}{|l|}{ Substrates } \\
\hline Albumin & 25 & $2 \cdot 1$ & $4 \cdot 7$ & 83 & 76 & 78 & 88 & 94 \\
\hline Total bilirubin & 27 & $0 \cdot 7$ & $7 \cdot 3$ & 108 & 98 & 102 & 114 & 118 \\
\hline Calcium & 29 & $1 \cdot 3$ & $3 \cdot 5$ & 101 & 97 & 100 & 102 & 104 \\
\hline Cholesterol & 27 & 86 & 241 & 94 & 91 & 93 & 96 & 98 \\
\hline Creatinine Jaffe & 23 & $0 \cdot 4$ & $6 \cdot 9$ & 105 & 97 & 100 & 102 & 108 \\
\hline Creatinine enz. & 19 & $0 \cdot 7$ & $7 \cdot 1$ & 108 & 98 & 101 & 112 & 113 \\
\hline Glucose & 23 & 41 & 305 & 105 & 99 & 103 & 107 & 108 \\
\hline Inorganic phosphate & 27 & $2 \cdot 0$ & $8 \cdot 4$ & 105 & 93 & 99 & 109 & 110 \\
\hline Iron & 27 & 68 & 268 & 97 & 86 & 93 & 100 & 102 \\
\hline Total protein & 29 & $4 \cdot 1$ & $8 \cdot 9$ & 103 & 99 & 101 & 106 & 107 \\
\hline Triglyzerides & 27 & 50 & 251 & 90 & 83 & 87 & 96 & 99 \\
\hline Urea & 29 & 14 & 169 & 99 & 94 & 96 & 102 & 105 \\
\hline Uric acid & 27 & $2 \cdot 6$ & $10 \cdot 8$ & 101 & 95 & 100 & 105 & 107 \\
\hline \multicolumn{9}{|l|}{ Electrolytes } \\
\hline Sodium & 25 & 111 & 163 & 99 & 98 & 99 & 100 & 101 \\
\hline Potassium & 25 & $2 \cdot 3$ & $7 \cdot 3$ & 100 & 98 & 100 & 101 & 103 \\
\hline Chloride & 19 & 84 & 124 & 101 & 96 & 97 & 103 & 104 \\
\hline
\end{tabular}




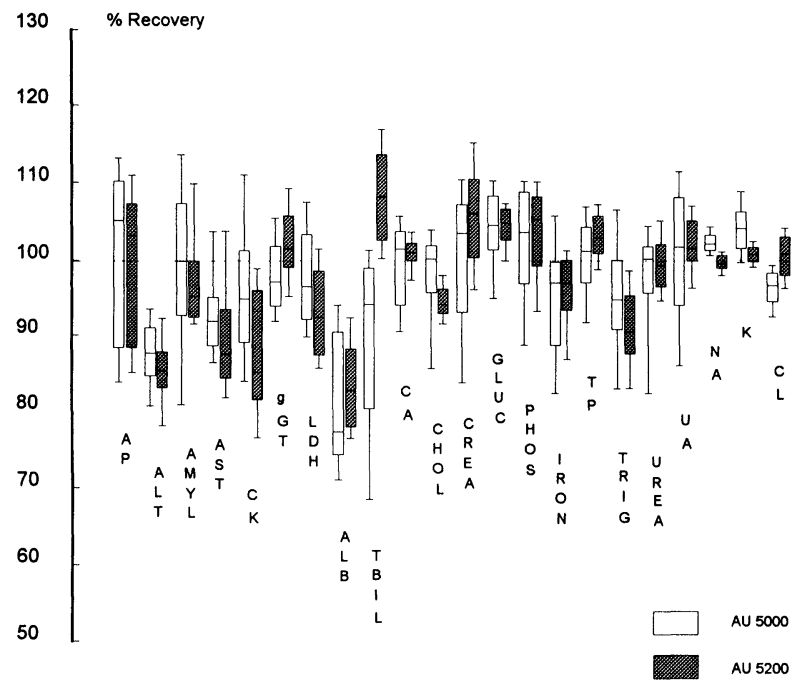

Figure 2. Recovery of assigned values in 32 commercial control materials on both the AU 5200 and the comparison instrument. The boxes represent the 25th, 75th percentiles and medians, the bars the 10th and 90th percentiles of the recovery ratios in percentages.

and ISE tests were performed continuously over a period of $6 \mathrm{~h}$. Therefore a serum pool was prepared, filtered and stirred on a magnetic stirrer at $4^{\circ} \mathrm{C}$. Approximately 1800 aliquots of this serum pool were taken and analysed in the AU 5200 immediately. Blank readings and calibration of the instrument were performed only once at the start of the experiments.

\section{Results}

\section{Imprecision}

Data on within-run and between-day imprecision are summarized in table 4 . The values are medians from three independent measurement series for seven control sera. Figures $1(a)$ and $1(b)$ show coefficients of variation for all tests on both the AU 5200 and AU 5000 analysers. The $\mathrm{CV}$ values in these figures are again medians taken across the $\mathrm{GV}$ values in table 4 and corresponding values obtained from measurements on the AU 5000 analyser.

As indicated in figure $1(a), 21$ of 23 evaluated tests on the AU 5200 analyser yielded a median within-run imprecision well below $2 \cdot 0 \%$; urea showed a median imprecison of $2 \cdot 1 \%$. Creatinine, measured with the kinetic Jaffe reaction method on the AU 5200, yielded rather high $\mathrm{CV}$ values from $1.5 \%$ to $4.7 \%$ (not shown in figures $1(a)$ and $1(b)$.

The electrolyte measurements on the AU 5200 analyser showed a remarkably good precision. Slightly lower median $\mathrm{CV}$ values for the imprecision in series were found for 18 of 22 tests on the AU 5200, compared with the AU 5000 analyser.

The median between-day $\mathrm{CV}$ values were below $3 \cdot 0 \%$ for 19 out of 23 tests on the AU 5200 analyser and were well below $5.0 \%$ for all tests, with the exception of the CPK activity measurement which showed $\mathrm{CV}$ values from $6 \cdot 1 \%$ to $15 \cdot 7 \%$.

The majority of all tests gave lower imprecision from day to day on the AU 5200 analyser compared to those on the AU 5000.

The overall precision in series and from day to day on both analysers could be rated as very good, with the AU 5200 performing slightly better than the AU 5000 analyser.

Table 6. Limits of the analytical range.

\begin{tabular}{|c|c|c|c|c|}
\hline \multirow[b]{2}{*}{ Analyte } & \multirow[b]{2}{*}{ Unit } & \multirow{2}{*}{$\begin{array}{c}\text { Measured } \\
\text { up to }\end{array}$} & \multicolumn{2}{|c|}{ Upper limit of linearity } \\
\hline & & & Found & Declared \\
\hline \multicolumn{5}{|l|}{ Enzymes } \\
\hline Alkaline phosphatase & $\mathrm{U} / 1$ & $3300^{3}$ & 3300 & 1600 \\
\hline Alanine aminotransferase & $\mathrm{U} / 1$ & 700 & 600 & 400 \\
\hline Amylase & $\mathrm{U} / 1$ & $1000^{3}$ & 1000 & 1350 \\
\hline Creatine phosphokinase & $\mathrm{U} / 1$ & 1200 & 1200 & 1100 \\
\hline g-Glutamyl-transferase & $\mathrm{U} / 1$ & 900 & 900 & 500 \\
\hline Lactate dehydrogenase & $\mathrm{U} / 1$ & 2500 & 1750 & 500 \\
\hline \multicolumn{5}{|l|}{ Substrates } \\
\hline Albumin & $\mathrm{g} / \mathrm{dl}$ & $7 \cdot 0$ & $7 \cdot 0$ & $7 \cdot 0$ \\
\hline Total bilirubin & $\mathrm{mg} / \mathrm{dl}$ & $25 \cdot 0$ & $25 \cdot 0$ & $30 \cdot 0$ \\
\hline Calcium & $\mathrm{mmol} / \mathrm{l}$ & $7 \cdot 0$ & $6 \cdot 0$ & $5 \cdot 0$ \\
\hline Creatinine enz. ${ }^{1}$ & $\mathrm{mg} / \mathrm{dl}$ & 30 & 30 & 20 \\
\hline Glucose $^{2}$ & $\mathrm{mg} / \mathrm{dl}$ & 1000 & 1000 & 700 \\
\hline Inorganic phosphate & $\mathrm{mg} / \mathrm{dl}$ & $22 \cdot 5$ & $22 \cdot 5$ & 20 \\
\hline Iron & $\mathrm{ug} / \mathrm{dl}$ & 1000 & 1000 & 1000 \\
\hline Total protein & $\mathrm{g} / \mathrm{dl}$ & $12 \cdot 0$ & $12 \cdot 0$ & $12 \cdot 0$ \\
\hline Triglyzerides & $\mathrm{mg} / \mathrm{dl}$ & 1200 & 1000 & 1000 \\
\hline Urea & $\mathrm{mg} / \mathrm{dl}$ & 400 & 375 & 300 \\
\hline Uric Acid & $\mathrm{mg} / \mathrm{dl}$ & $33 \cdot 0$ & $33 \cdot 0$ & $20 \cdot 0$ \\
\hline
\end{tabular}

\footnotetext{
${ }^{1}$ Creatinine PAP (Merck); ${ }^{2}$ Hexokinase method; ${ }^{3}$ Extinction beyond DOD range.
} 

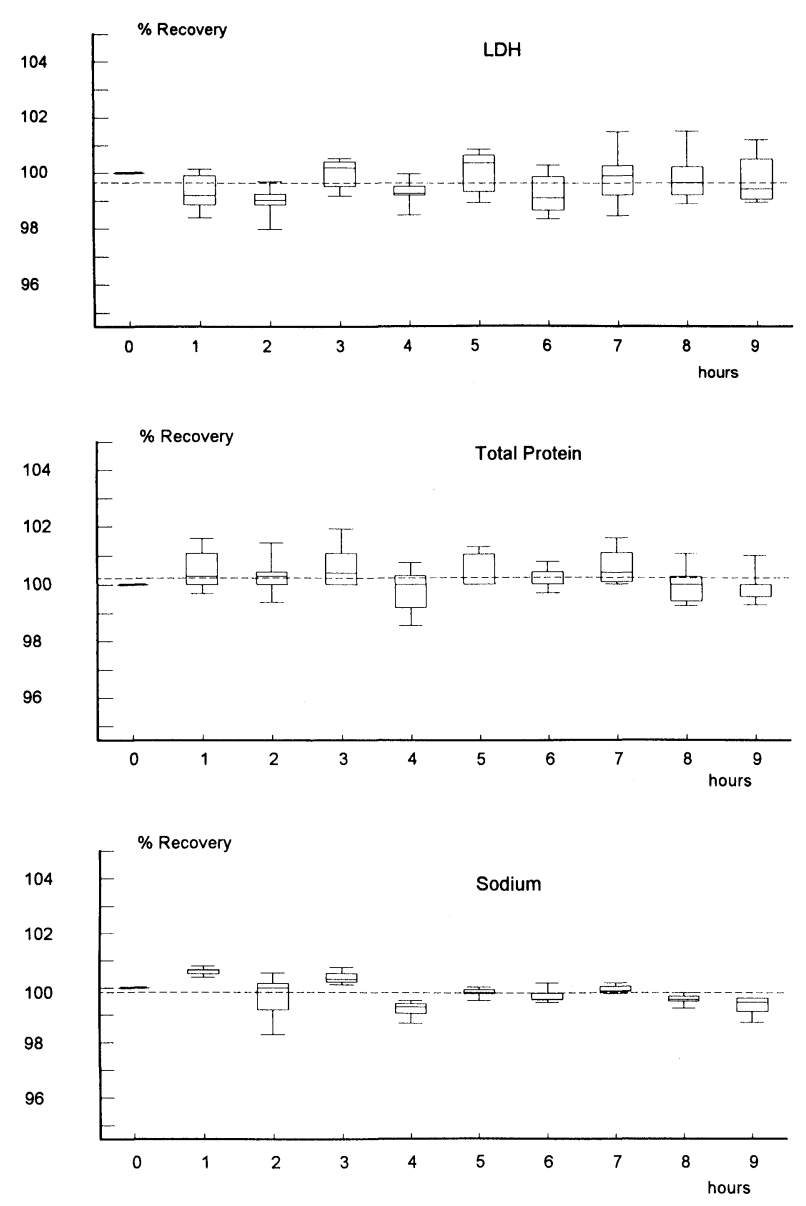

Figure 3 (a). Drift during $9 \mathrm{~h}$ for three representative analytes measured in seven control sera. The medians, 10th, 25th, 75th and 90th percentiles of the recovery ratios in relation to the initial measurements are shown as box-plots.

\section{Assessment of accuracy}

The recovered values of all analytes in 32 commercial control sera were expressed as percentages of the assigned values. The medians, the 10th, 25th, 75th and 90th percentiles of the respective values are shown in table 5 and in figure 2. Fourteen of 23 tests yielded median recoveries within the $5 \%$ range; five tests were in the range between $5 \%$ and $10 \%$ (lactate dehydrogenase, bilirubin, cholesterol, triglyzerides and creatinine measured enzymatically); and three tests were in the range between $10 \%$ and $15 \%$ (alanine aminotransferase, creatine phosphokinase).

The low recoveries of some enzyme activity tests may be due to the conversion of the values measured to corresponding values at $25^{\circ} \mathrm{C}$. These conversion factors are based upon human serum, whereas most commercial control materials are essentially non-human or spiked with non-human analytes. The low recoveries of albumin $(83 \%)$, cholesterol and triglyzerides were caused by calibration errors. As a consequence of this evaluation the calibrator values for these tests were reassigned by the manufacturer.

\section{Linearity}

Both the linearities found, and the linearity ranges given by the manufacturers, are shown in table 6 . The
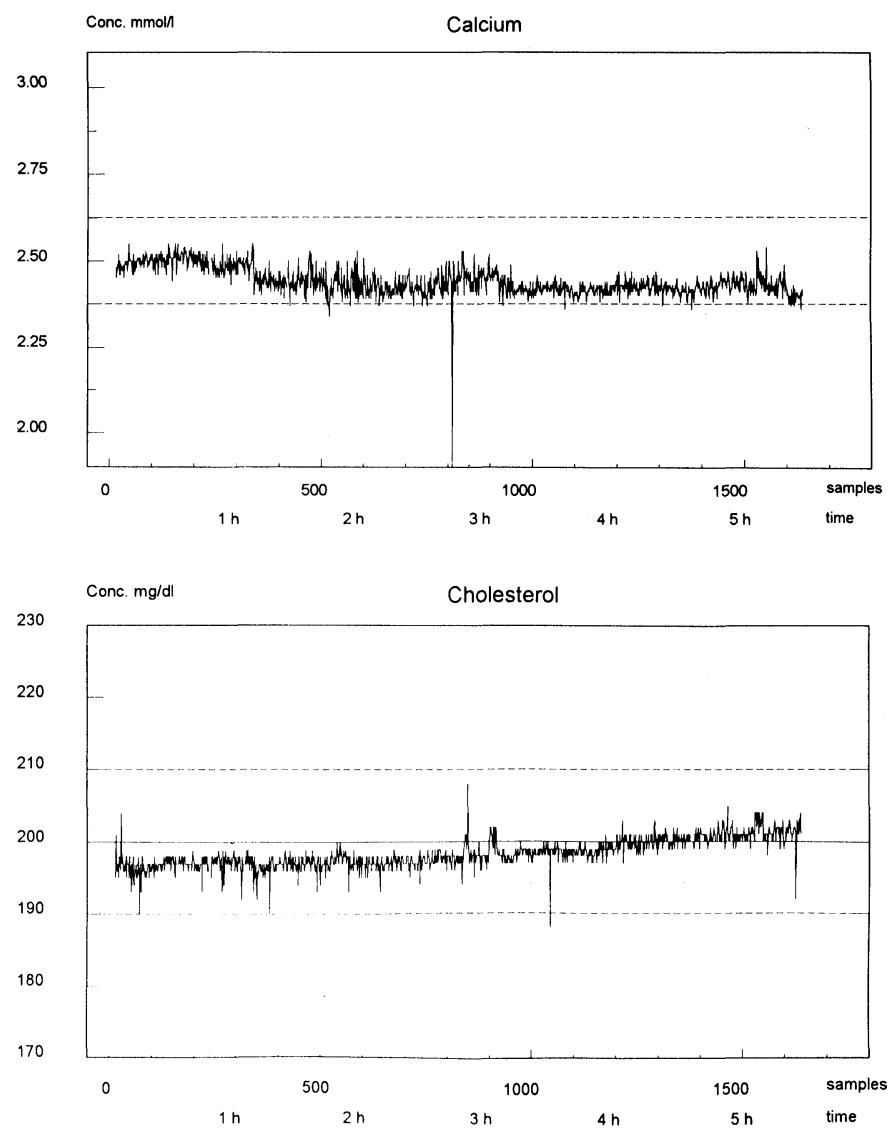

Figure 3 (b). Drift during $6 h$ of continuous operation. Approximately 1800 measurements of all analytes were performed.

linearities found were better than the manufacturers' for all tests, with the exception of amylase. The transaminases showed limited linearities with an upper range of approximately $500 \mathrm{U} / \mathrm{I}$, whereas cholesterol and triglyceride measurement is possible up to $1000 \mathrm{mg} / \mathrm{dl}$.

\section{Carry-over}

A potential carry-over of sample residue resulting from an insufficient washing of the cuvettes was investigated by measuring creatine phospokinase activity $(27 \mathrm{U} / 1$ in a serum pool) in cuvettes which had been used for the determination of the same analyte with a very high activity (approximately $1500 \mathrm{U} / 1$ ). The results were compared with measurements of low activity in cuvettes which had also been used for measurements of low activity. Figure 4(a) shows that there was no detectable difference. Sample carry-over due to incomplete washing of the probe needle and the mixer blades was investigated by alternating two serum pools with high and low creatine phosphokinase activity; the samples which immediately followed the groups with high activity did not show elevated activities (figure $4(b)$ ). In conclusion, no specimen-related carry-over could be detected.

\section{Method comparison with patient samples}

The Olympus AU 5200 series analyser was compared with an Olympus AU 5000 analyser and a Hitachi 747 analyser (ISE measurements only). The statistical evaluation was performed according to the method of Passing and Bablock [3]. The numerical results are given in 


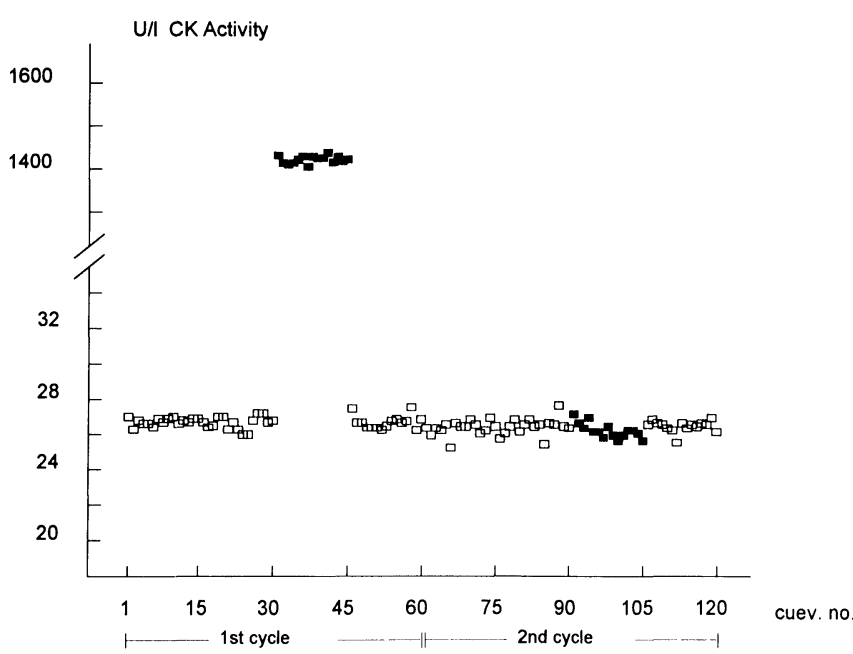

Figure 4 (a). Specimen related carry-over due to incomplete cuvette washing: creatine phosphokinase measurements of 120 samples of two serum pools with a low and a high activity in two complete cuvette wheel cycles. During the first cycle samples with a high activity (approximately $1500 \mathrm{U} / \mathrm{l}$ ) were measured in cuvettes 31 to 45. In the same cuvettes samples with a low activity were measured during the second cycle (indicated by filled squares).

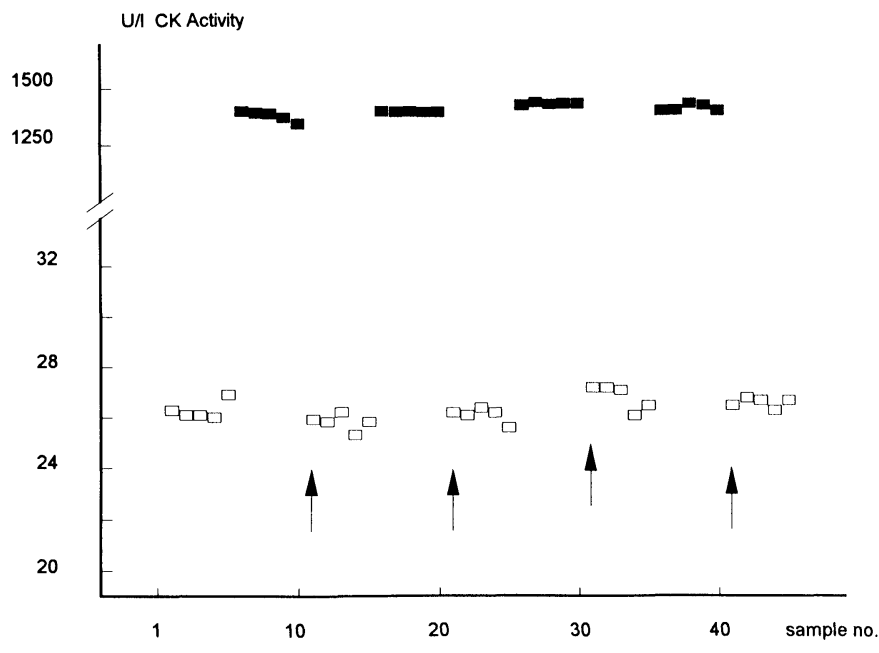

Figure 4 (b). Specimen related carry-over due to incomplete washing of the probe needles and mixer blades. Groups of five samples with low and high activity of creatine phosphokinase were alternated several times. The arrow bars mark the first samples with low activity immediately following a sequence of samples with high activity.

table 7, and scatterplots are shown in figure 5 . The correlations were close for all enzyme and substrate tests. Good agreement was found between flame photometry (AU 5000) and ISE measurement (Hitachi 747) for potassium. Sodium (flame photometry and ISE) and chloride measurement (mercury thiocyanate) showed lower coefficients of correlation.

Alkaline phosphatase, creatine phosphokinase, g-glutamyltransferase, aspartate aminotransferase, alanine aminotransferase, lactate dehydrogenase, calcium, creatinine (measured enzymatically), inorganic phosphate, total bilirubin, triglyzerides, urea, uric acid, potassium (flame photometry and ISE), sodium (flame photometry) and chloride (mercury thiocyanate method and ISE) did not show a significant deviation from the factor 1 for the slope or from the constant 0 for the intercept. Albumin, cholesterol, glucose (hexokinase method), iron, total protein and sodium (ISE) measurements showed small, but significant, deviation of slope or intercept. Amylase measurements on both analysers correlated well, but are not comparable without data transformation due to different test methods with different amylase substrates.

Possible reason for the discrepancies in the albumin and cholesterol assays could be incorrect calibrator values (see above), or, in the case of iron, to different test methodologies (see table 2).

\section{Drift}

The results of the drift experiments are displayed in figures $3(a)$ (measurements every hour for $9 \mathrm{~h}$ ) and $3(b)$ (continuous measurements for $6 \mathrm{~h}$ ). A continuous trend either increasing or decreasing could not be detected for any of the parameters tested. Median deviations from the initial values did not exceed $5 \%$ over $9 \mathrm{~h}$ for any test. The electrolyte measurements showed exceptionally low deviations from the starting value, indicating a very stable ISE system. The second drift experiment revealed short-term fluctuations in the measurement of creatinine (Jaffe method). Statistical spectral analysis yielded a fourier frequency of about $0 \cdot 05$, which is equivalent to an oscillation period of 20 samples. The remaining tests did not show any periodic variations or sudden fluctuations.

\section{Assessment of practicability}

An instruction period of four days was necessary to acquire the knowledge to operate the Olympus AU 5200 analyser, users of the older AU 5000 analyser can operate the new system instantly. Despite the size and capacity of the analyser, the Olympus AU 5200 is easy to run and can easily be integrated into the organization of a large laboratory. The sample feeding mechanism operates in a linear fashion, allowing continuous supply of subsequent samples. One sample which is nowadays not an aliquot, but delivered in a primary tube, passes through the instrument in $5 \mathrm{~min}$ and even tubes on a fully loaded sample tray are accessible after $70 \mathrm{~min}$. The sample belt is in front of the instrument, which is a major advantage over the older AU 5000 series analyser where it is in the rear. The analyser can be reached from all sites and all mechanical movements can be watched.

The system-processing software for routine operation is clearly arranged; the main jobs, for example activating the analyser out of a standby status, starting measurements, washing the cuvettes and flushing the reagent lines, are presented in one menue and are initiated by one keystroke. The software contains an extensive diagnostic program, which allows a specific detection of mechanical or electronic problems.

The preanalytical preparation of the analyser consists of four steps requiring the time periods given in parenthesis: warming up to $37^{\circ} \mathrm{C}$ (60 min), washing of cuvettes and 
Table 7. Method comparison studies in human sera with Olympus AU $5200(y)$ and comparison instrument $(x)$. Regression analyses $(y=a$ $+b x)$ were performed according to Passing and Bablock.

\begin{tabular}{|c|c|c|c|c|c|c|}
\hline Analyte & $N$ & $r$ & $b^{l}$ & $a^{2}$ & median $x$ & median $y$ \\
\hline \multicolumn{7}{|l|}{ Enzymes } \\
\hline Alkaline phosphatase & 223 & $1 \cdot 000$ & $1 \cdot 03$ & $0 \cdot 69$ & $124 \cdot 0$ & $129 \cdot 0$ \\
\hline Alanine aminotransferase & 242 & 0.993 & $0 \cdot 96$ & $-0 \cdot 85$ & $15 \cdot 5$ & $14 \cdot 0$ \\
\hline Amylase & 227 & $0 \cdot 995$ & $* 0 \cdot 33$ & $* 0 \cdot 27$ & $94 \cdot 0$ & $32 \cdot 0$ \\
\hline Aspartate aminotransferase & 242 & 0.999 & $1 \cdot 00$ & $-1 \cdot 00$ & $12 \cdot 0$ & $11 \cdot 0$ \\
\hline Creatine phosphokinase & 219 & 0.993 & $0 \cdot 89$ & $1 \cdot 00$ & $25 \cdot 0$ & $23 \cdot 0$ \\
\hline g-Glutamyltransferase & 237 & $0 \cdot 999$ & 1.09 & $0 \cdot 00$ & $26 \cdot 0$ & $28 \cdot 0$ \\
\hline Lactate dehydrogenase & 234 & $0 \cdot 997$ & $0 \cdot 93$ & $1 \cdot 60$ & $185 \cdot 5$ & $177 \cdot 0$ \\
\hline \multicolumn{7}{|l|}{ Substrates } \\
\hline Albumin & 239 & $0 \cdot 977$ & 0.93 & $*-0 \cdot 19$ & $3 \cdot 89$ & $3 \cdot 43$ \\
\hline Total bilirubin & 231 & 0.999 & $1 \cdot 11$ & $-0 \cdot 06$ & $0 \cdot 70$ & $0 \cdot 70$ \\
\hline Calcium & 239 & 0.963 & $1 \cdot 00$ & 0.03 & $2 \cdot 34$ & $2 \cdot 37$ \\
\hline Cholesterol & 234 & $0 \cdot 997$ & $0 \cdot 95$ & $*-1.54$ & $186 \cdot 5$ & $174 \cdot 5$ \\
\hline Creatinine enz. & 243 & $0 \cdot 997$ & $1 \cdot 00$ & $0 \cdot 00$ & $1 \cdot 10$ & $1 \cdot 10$ \\
\hline Glucose & 243 & $0 \cdot 997$ & 0.99 & $* 1 \cdot 06$ & $114 \cdot 0$ & $115 \cdot 0$ \\
\hline Inorganic phosphate & 233 & 0.991 & $0 \cdot 98$ & $0 \cdot 08$ & $3 \cdot 70$ & $3 \cdot 80$ \\
\hline Iron & 216 & $0 \cdot 991$ & $* 1 \cdot 02$ & $-5 \cdot 86$ & $87 \cdot 5$ & $80 \cdot 5$ \\
\hline Total protein & 231 & $0 \cdot 971$ & $* 1 \cdot 04$ & $*-0 \cdot 14$ & $6 \cdot 90$ & $6 \cdot 90$ \\
\hline Triglyzerides & 235 & 0.999 & $0 \cdot 93$ & $1 \cdot 69$ & $143 \cdot 0$ & $133 \cdot 0$ \\
\hline Urea & 238 & $0 \cdot 998$ & $1 \cdot 04$ & $-1 \cdot 74$ & $42 \cdot 0$ & $41 \cdot 0$ \\
\hline Uric acid & 235 & 0.992 & $1 \cdot 00$ & $-0 \cdot 20$ & $5 \cdot 70$ & $5 \cdot 60$ \\
\hline \multicolumn{7}{|l|}{ Electrolytes } \\
\hline Sodium & 291 & $0 \cdot 834$ & $1 \cdot 00$ & -3.00 & $149 \cdot 0$ & $147 \cdot 0$ \\
\hline \multirow{2}{*}{\multicolumn{7}{|c|}{$\begin{array}{l}\text { AU } 5200 \text { ISE }(y) \\
\text { AU } 5000 \text { Flame }(x)\end{array}$}} \\
\hline & & & & & & \\
\hline Sodium & 299 & $0 \cdot 879$ & $* 0 \cdot 90$ & $* 11 \cdot 10$ & $151 \cdot 0$ & $147 \cdot 0$ \\
\hline \multirow{2}{*}{\multicolumn{7}{|c|}{$\begin{array}{l}\text { AU } 5200 \text { ISE }(y) \\
\text { Hit } 747 \text { ISE }(x)\end{array}$}} \\
\hline & & & & & & \\
\hline Potassium & 287 & $0 \cdot 956$ & $1 \cdot 00$ & $-0 \cdot 10$ & $4 \cdot 70$ & $4 \cdot 50$ \\
\hline \multirow{2}{*}{\multicolumn{7}{|c|}{$\begin{array}{l}\text { AU } 5200 \text { ISE }(y) \\
\text { AU } 5000 \text { Flame }(x)\end{array}$}} \\
\hline & & & & & & \\
\hline Potassium & 298 & 0.989 & $1 \cdot 00$ & $-0 \cdot 10$ & $4 \cdot 65$ & $4 \cdot 50$ \\
\hline \multirow{2}{*}{\multicolumn{7}{|c|}{ AU 5200 ISE (y) }} \\
\hline & & & & & & \\
\hline Chloride & 299 & $0 \cdot 864$ & $0 \cdot 85$ & $14 \cdot 00$ & $109 \cdot 0$ & $108 \cdot 0$ \\
\hline AU 5200 ISE (y) & & & & & & \\
\hline AU $5000 \mathrm{Hg}(\mathrm{x})$ & & & & & & \\
\hline Chloride & 297 & $0 \cdot 949$ & $0 \cdot 84$ & $16 \cdot 48$ & $110 \cdot 0$ & $108 \cdot 2$ \\
\hline \multicolumn{7}{|l|}{ AU 5200 ISE (y) } \\
\hline Hit 747 ISE (x) & & & & & & \\
\hline
\end{tabular}

*: ${ }^{1}$ Significant deviation of slope b from $1 \cdot 0 ;{ }^{2}$ significant deviation of intercept a from 0.

filling reagent lines (23 $\mathrm{min})$, reagent blanking, calibration and running controls $(20 \mathrm{~min})$. Using the automatic power-on facility reduces the preanalytic phase by the time period for warming up the instrument. Thus, after $45 \mathrm{~min}$, including the time needed for checking the results of calibration and control materials, the analyser is ready for routine operation.

During the evaluation period and the subsequent routine work no total shut down of the analyser occurred. The most frequent problems were rack jams on the transport belt and needle crashes. In such situations the analyser does not stop completely, but stops only the feeding mechanism. Results of tests pipetted so far can still be obtained. The most severe faults were worn out gears of the cuvette wheel motor causing a small displacement of the cuvette wheel hindering the action of the washer unit; and, a leakage in the vacuum system of the washer unit causing an incomplete draining of the cuvettes. Both problems could be attributed to some kind of material fatigue. The manufacturer has now replaced the materials for these machine parts. Another point of criticism is the badly arranged report format in which the results are printed out - there is no way of achieving patient-oriented reports.

\section{Conclusion}

With respect to imprecision, accuracy, linearity and carryover data, the Olympus AU 5200 analyser compared 
H. Mayer et al. Analytical performance of the selective multianalyser Olympus AU 5200

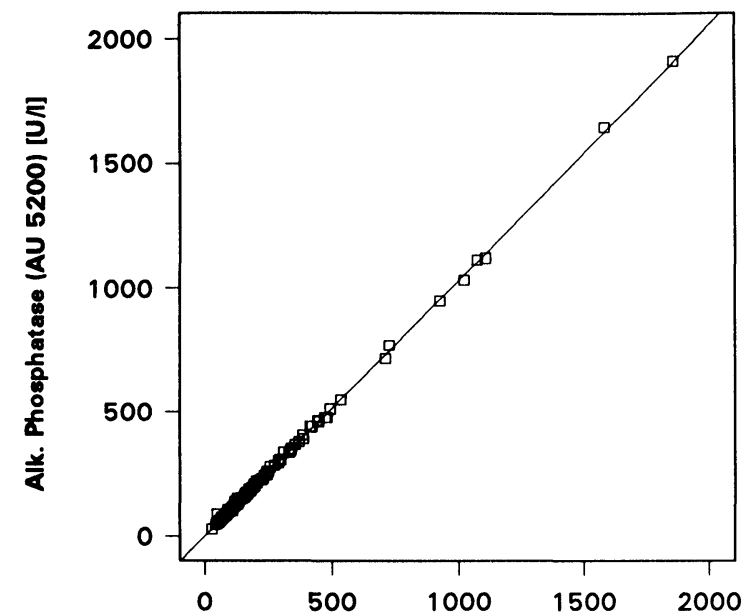

Alk. Phosphatase (AU 5000) [U/I]

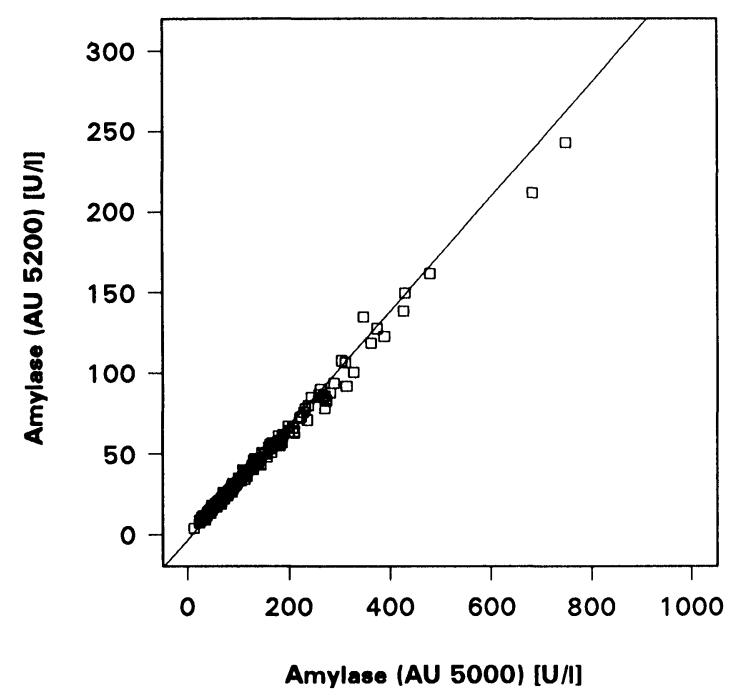

Amylase (AU 5000) [U/I]

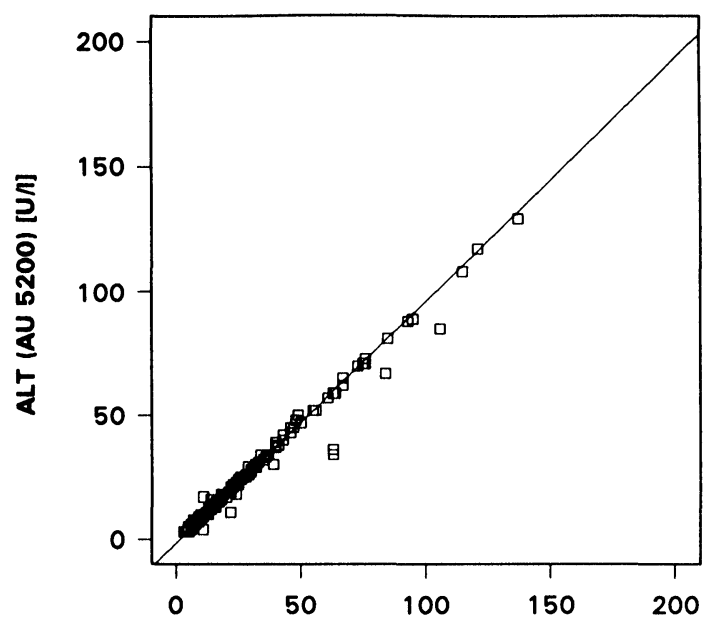

ALT (AU 5000) [U/I]
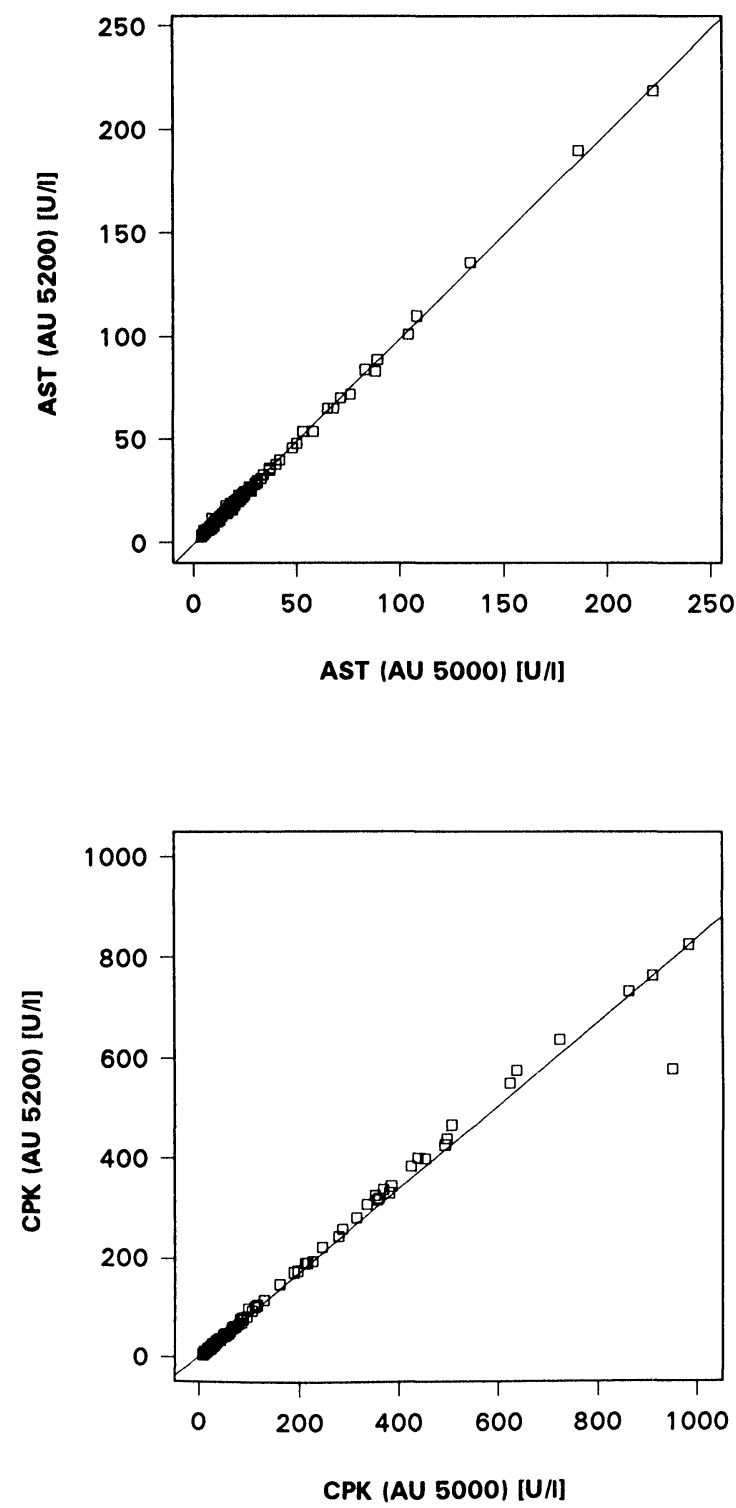

Figure 5 (a). Graphical plots of instrument comparison. 
H. Mayer et al. Analytical performance of the selective multianalyser Olympus AU 5200
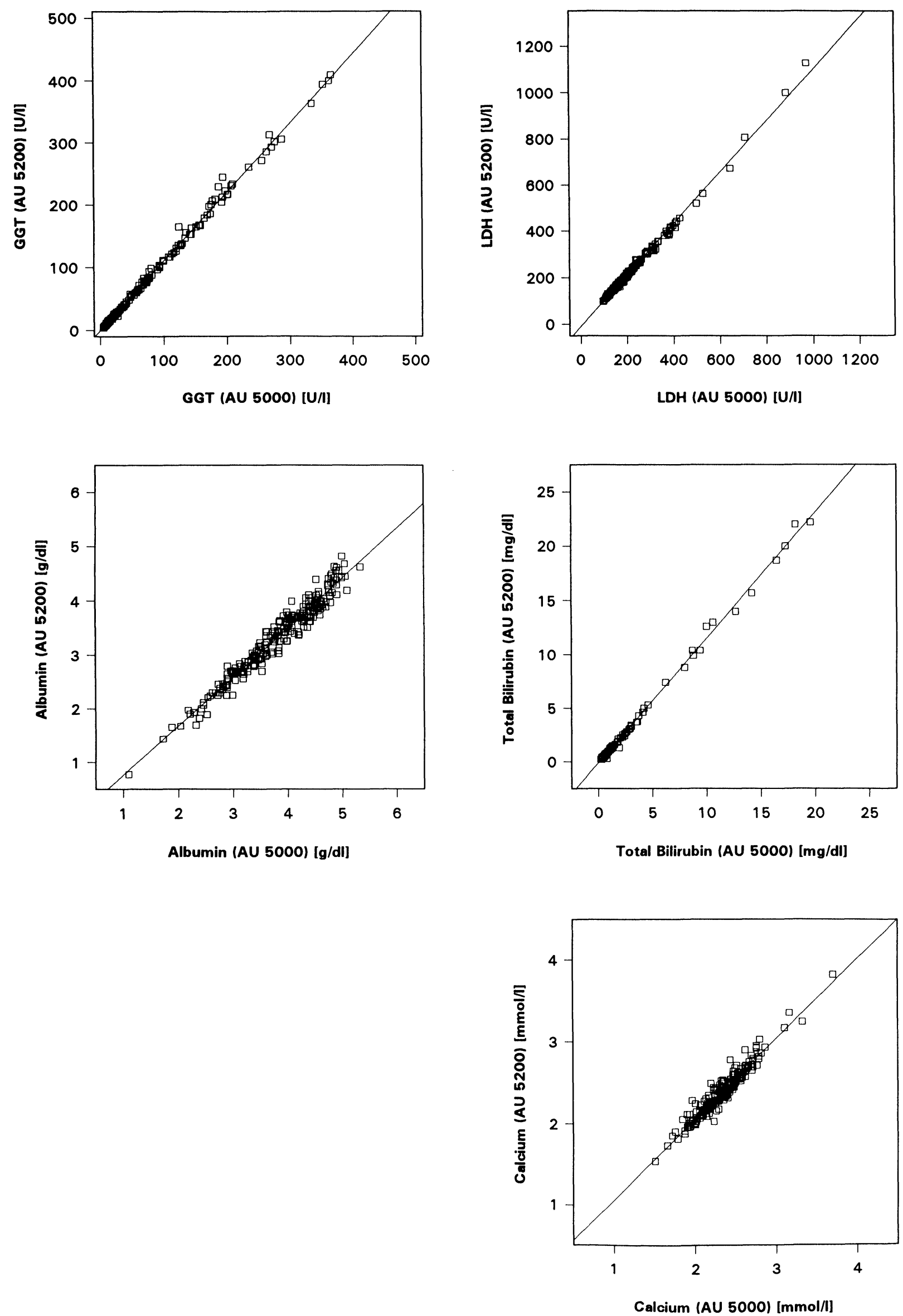

Figure 5 (b). Graphical plots of instrument comparison. 


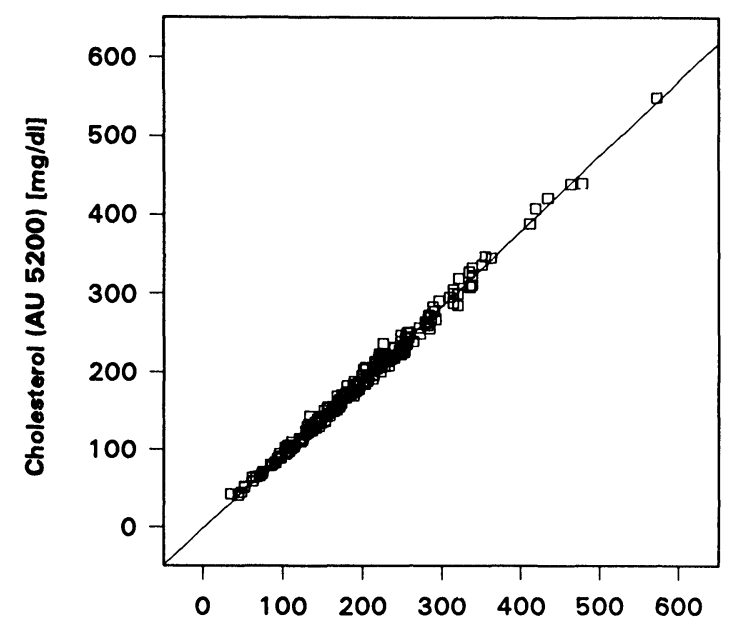

Cholesterol (AU 5000) [mg/dl]

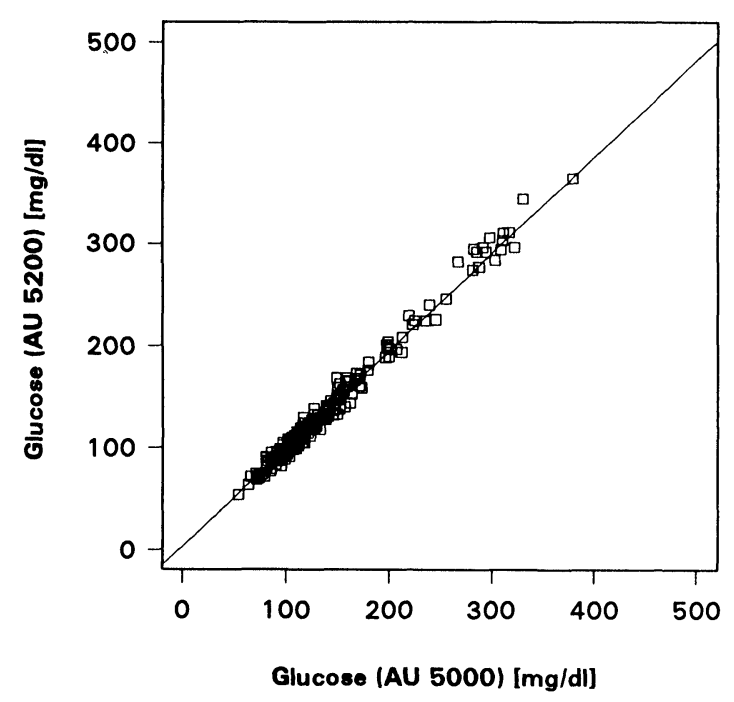

Glucose (AU 5000) [mg/dl]
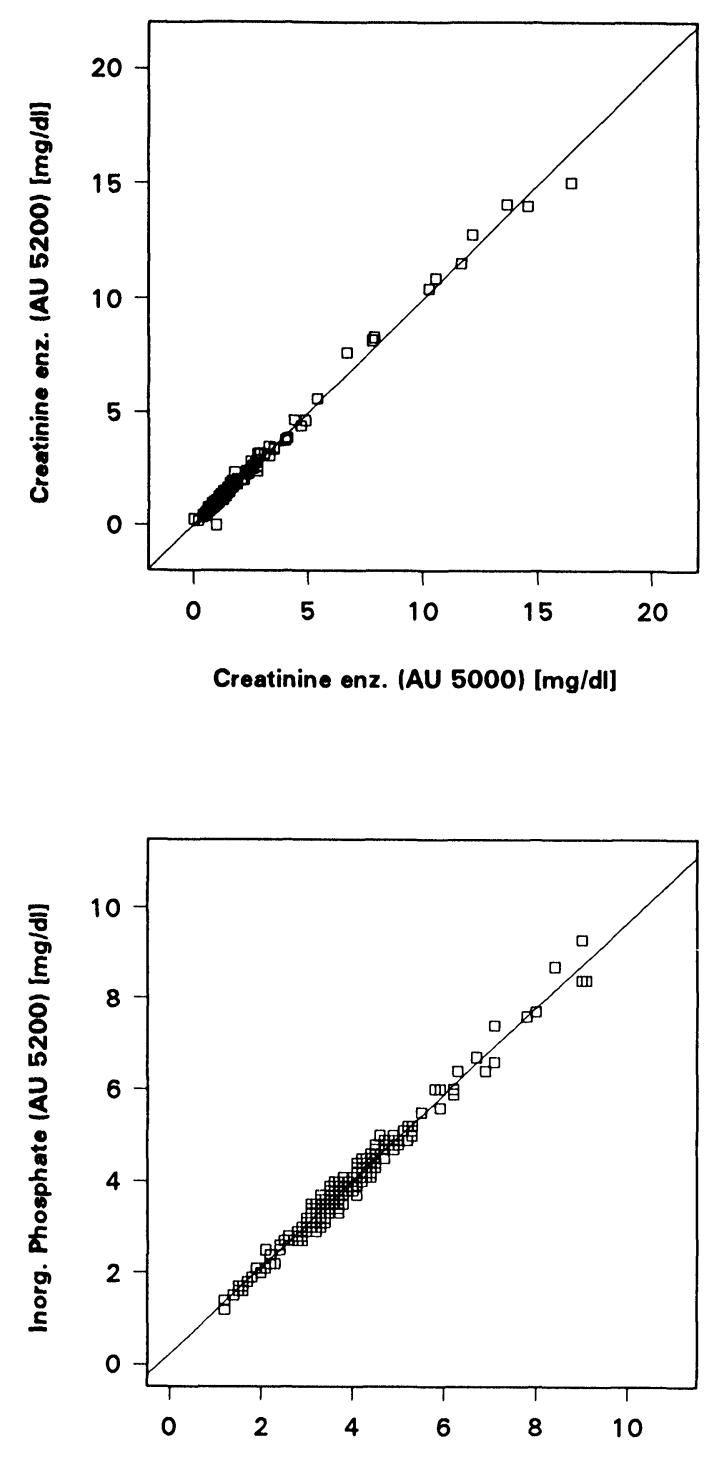

Inorg. Phosphate (AU 5000) [mg/dl]

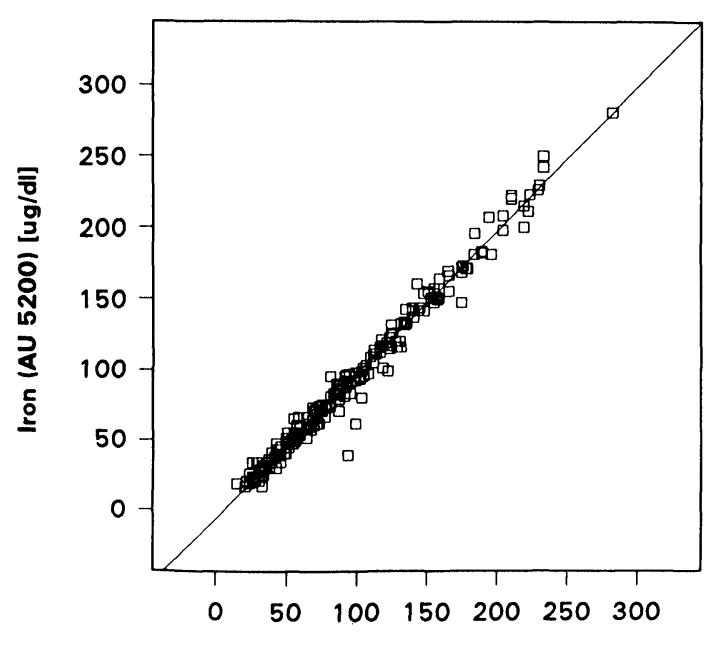

Iron (AU 5000) [ug/dl]

Figure 5 (c). Graphical plots of instrument comparison. 
H. Mayer $e t$ al. Analytical performance of the selective multianalyser Olympus AU 5200

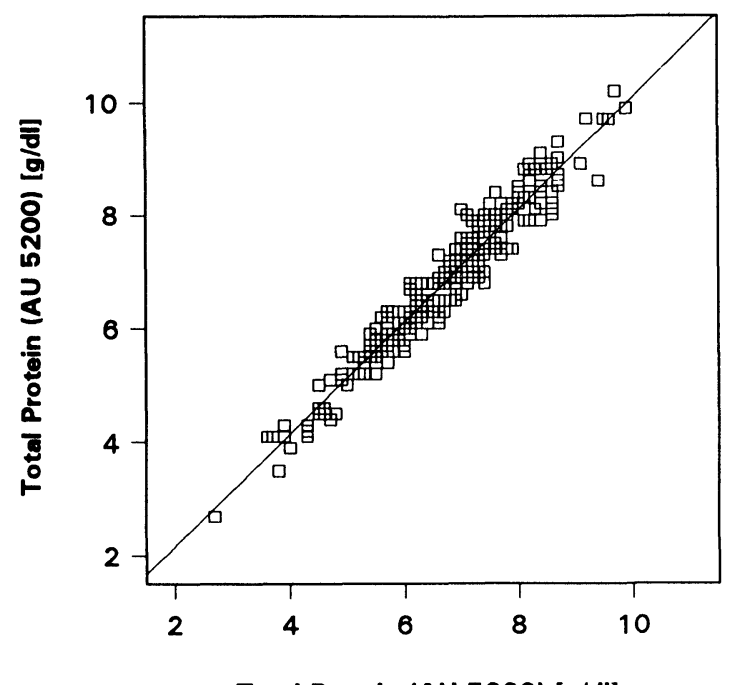

Total Protein (AU 5000) [g/dl]

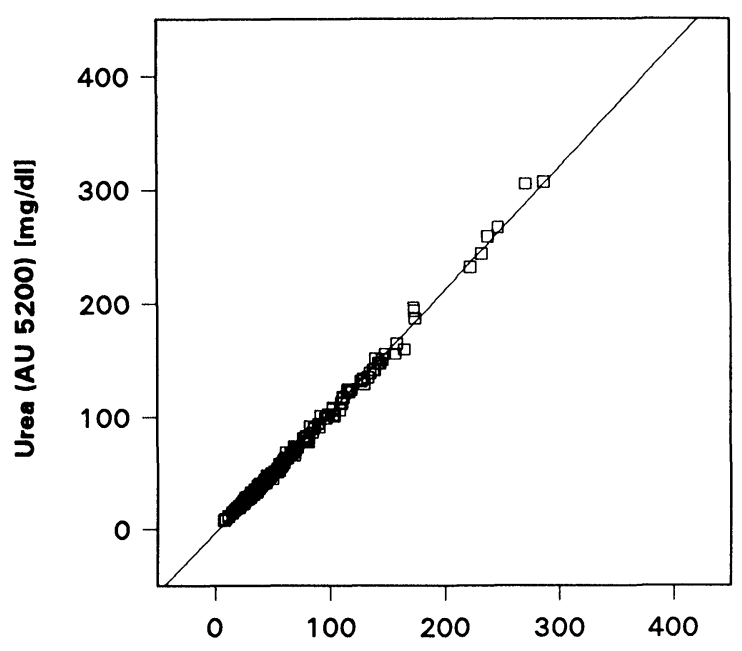

Urea (AU 5000) [mg/dl]
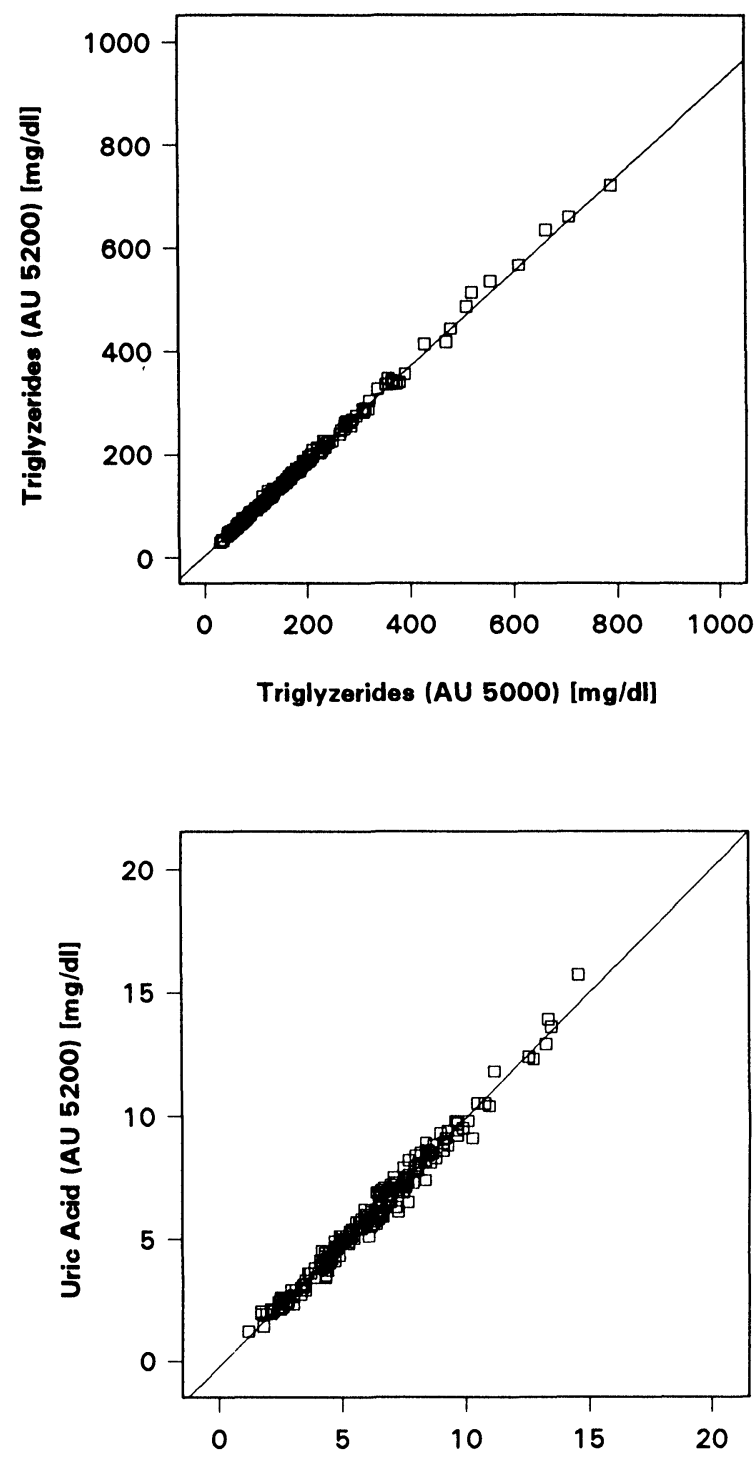

Uric Acid (AU 5000) [mg/dl]

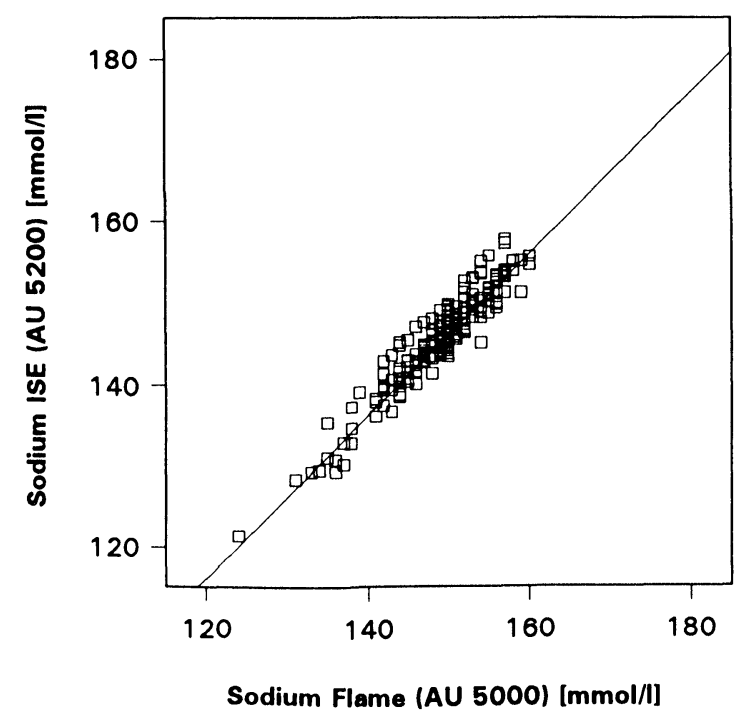

Figure $5(d)$. Graphical plots of instrument comparison. 
H. Mayer et al. Analytical performance of the selective multianalyser Olympus AU 5200
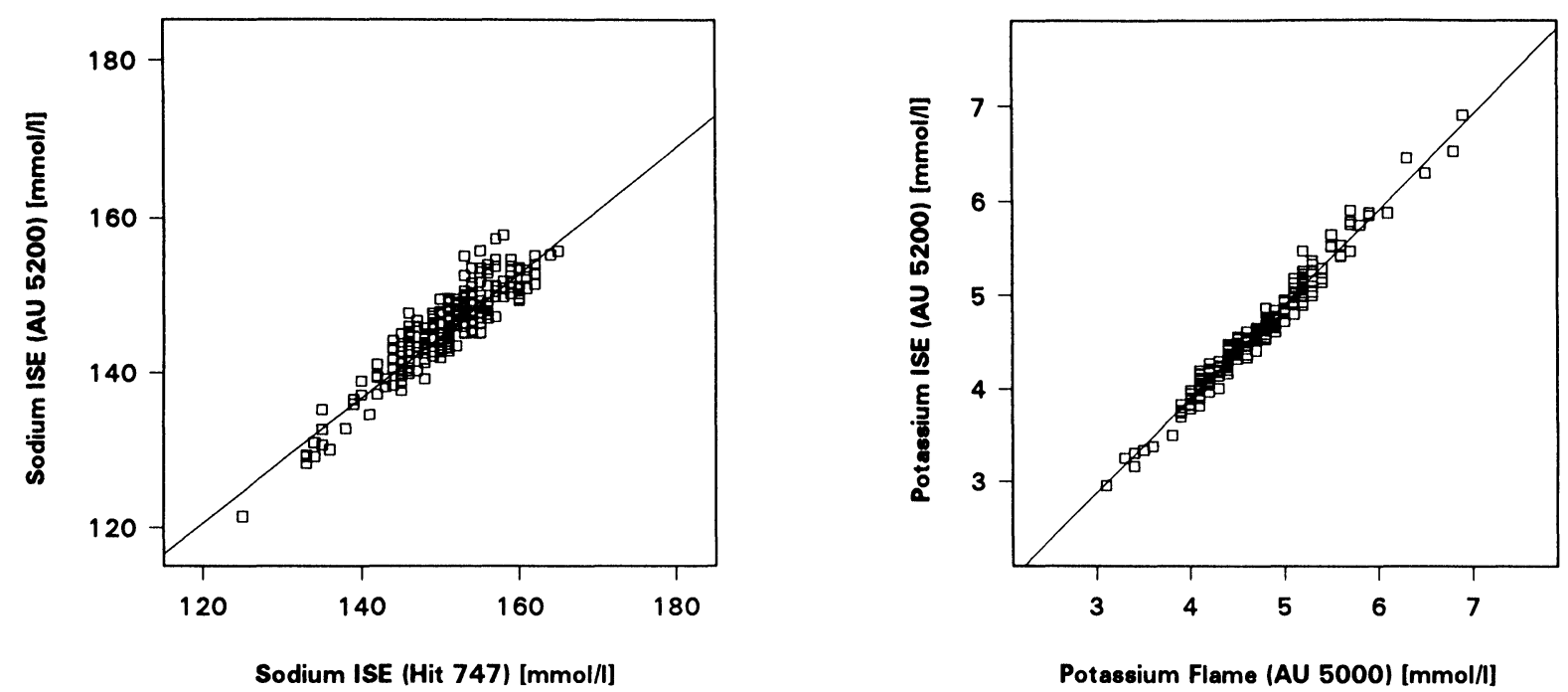

Potassium Flame (AU 5000) [mmol/l]
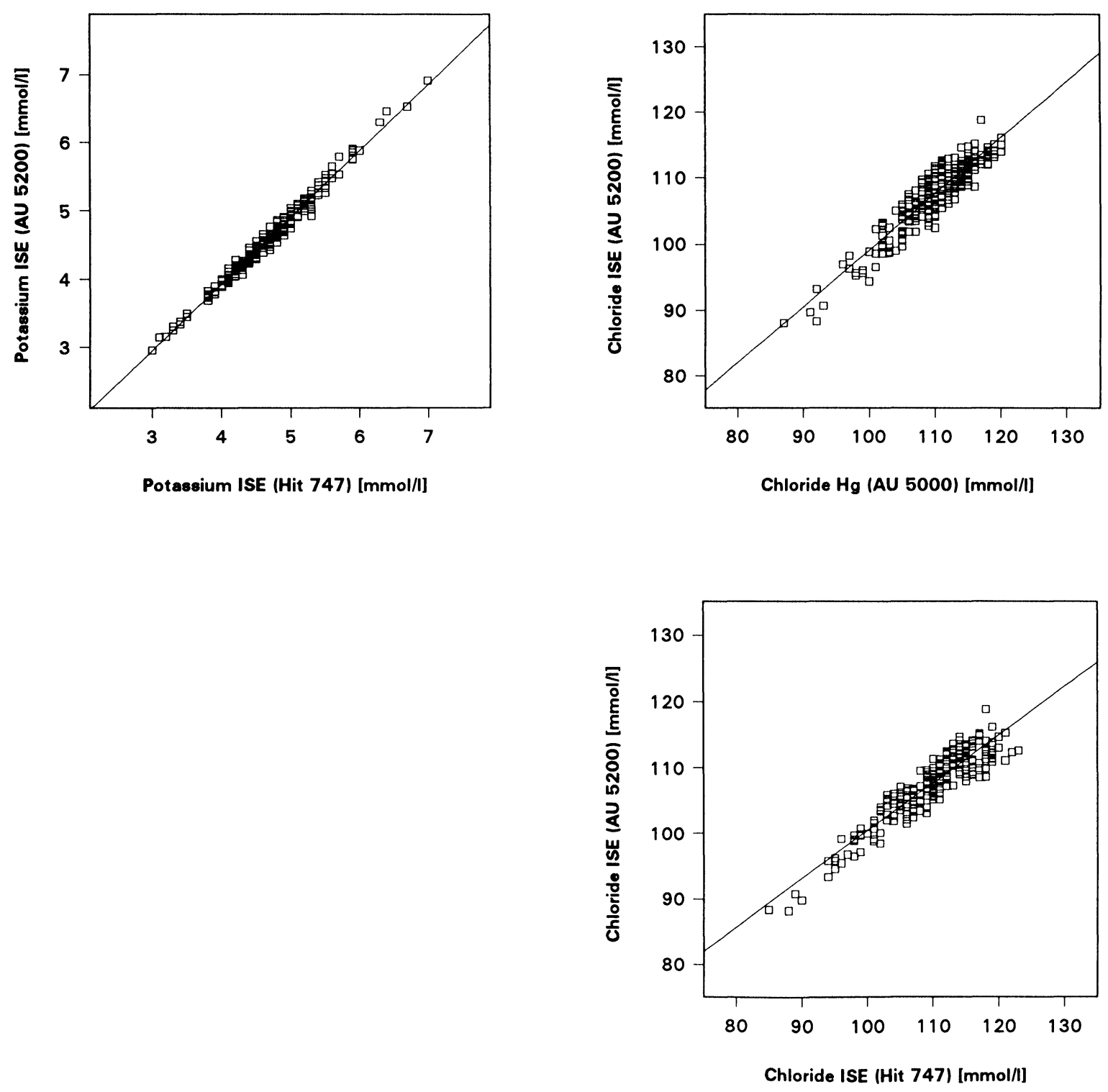

Figure 5 (e). Graphical plots of instrument comparison. 
H. Mayer et al. Analytical performance of the selective multianalyser Olympus AU 5200

favourably with and showed slightly better results than the AU 5000 analyser. The Olympus AU 5200 analyser reaches a sustained peak performance of $300 \mathrm{samples} / \mathrm{h}$ including ISE measurements, operates reliably from day to day and is thus well suited for medium and large sized laboratories.

\section{References}

1. Haeckel, R., Busch, E. W., Jennings, R. D., Korkholm, G. and Trughaud, A., ECCLS Document, 3, 2 (1986).

2. Luley, G., Struss, H. G. and Prellwitz, W., Journal of Automatic Chemistry, 1 (1990).

3. Passing, H. and Bablock, W. J., Clinical Chemistry and Biochemistry, 22 (1984). 


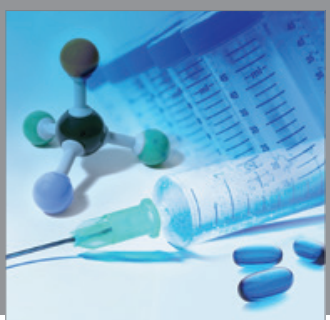

International Journal of

Medicinal Chemistry

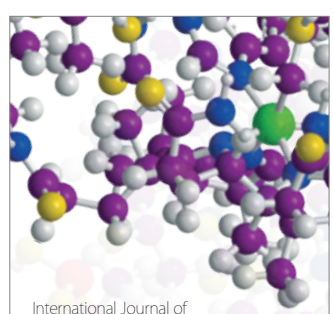

Carbohydrate Chemistry

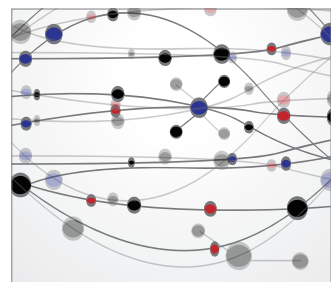

The Scientific World Journal
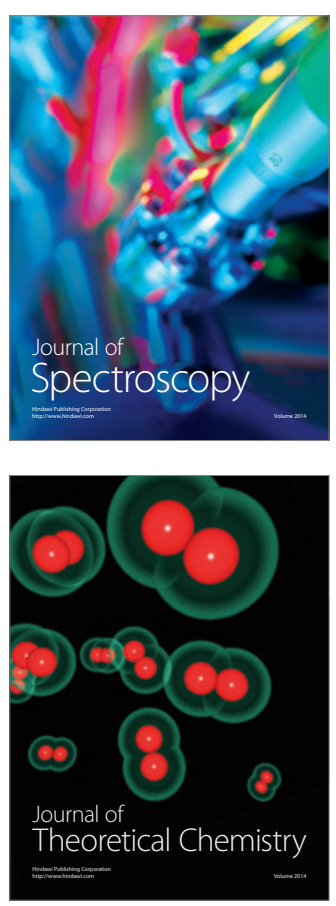
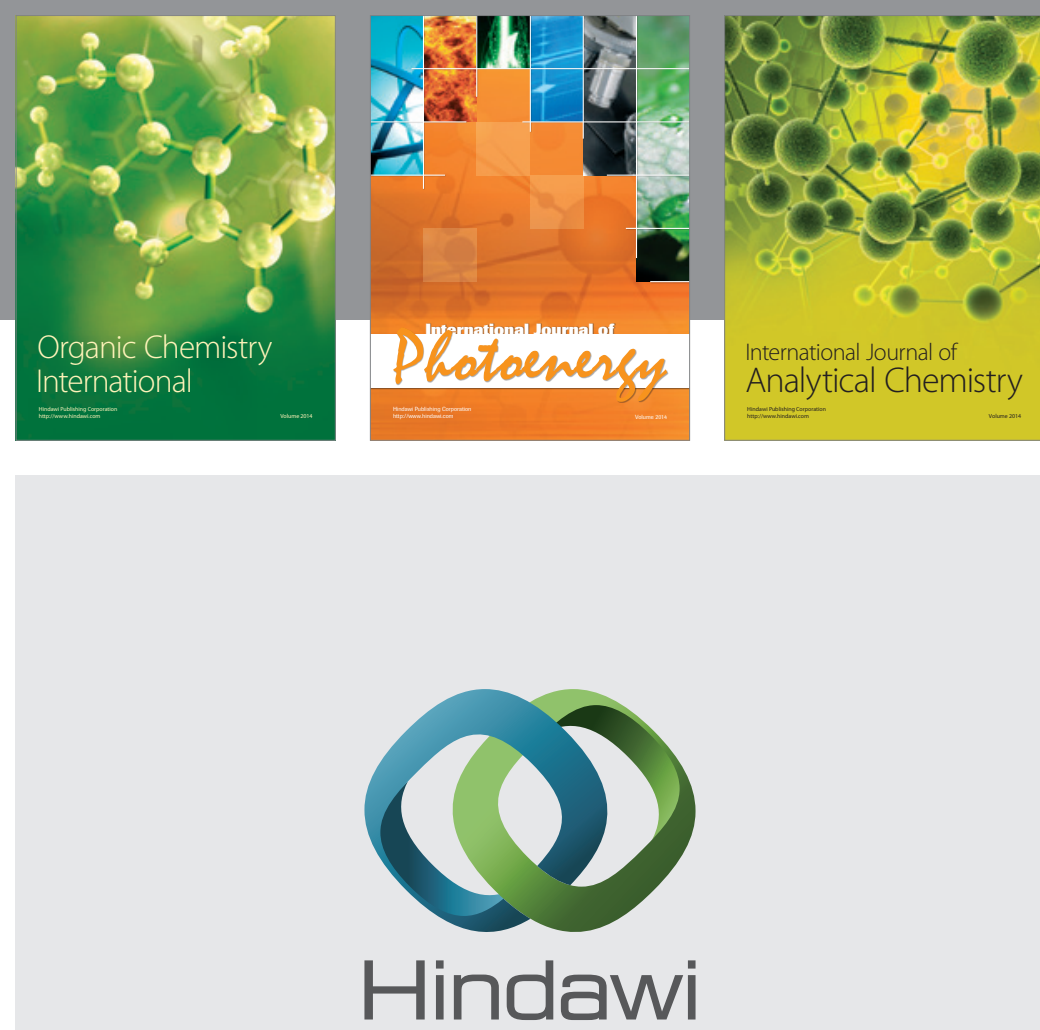

Submit your manuscripts at

http://www.hindawi.com
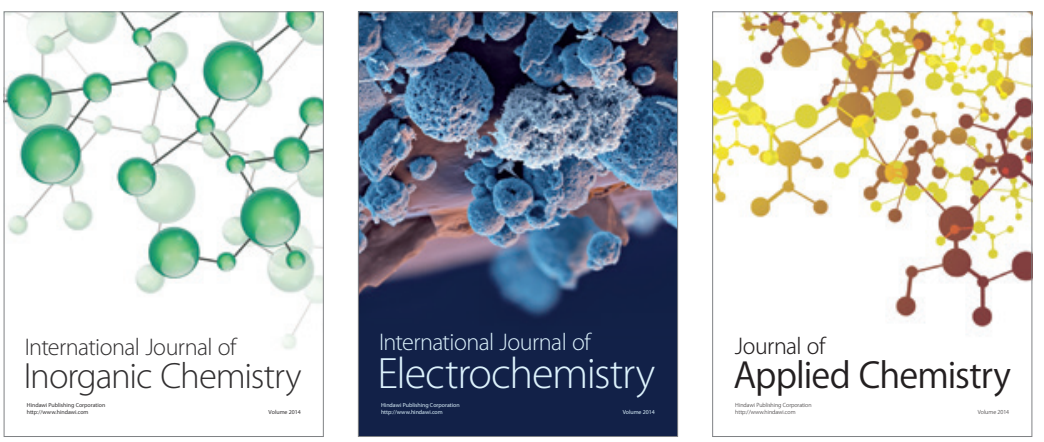

Journal of

Applied Chemistry
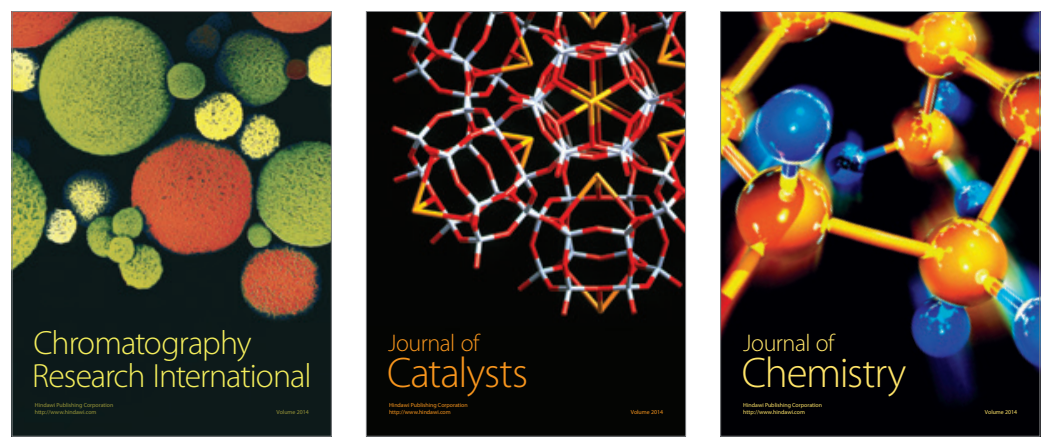
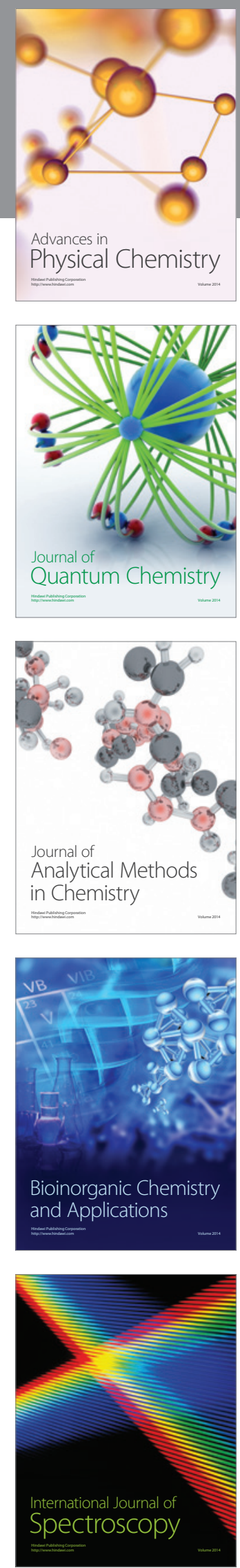